The submitted manuscript has been authored

by a contractor of the U.S. Government

under contract No. W-31-109ENG-38.

Accordingly, the U.S. Government retains a

nonexclusive, royalty-free license to publish

or reproduce the published form of this

contribution, or allaw others to do so, for

U. S. Government purposes.

\section{RECEIVED}

NOV 211995

OSTI

High-Heat-Load Synchrotron Tests of Room-Temperature, Silicon Crystal Monochromators at the CHESS F-2 Wiggler Station

W.-K. Lee, P. B. Fernandez, T. Graber, and L. Assoufid

Experimental Facilities Division, APS

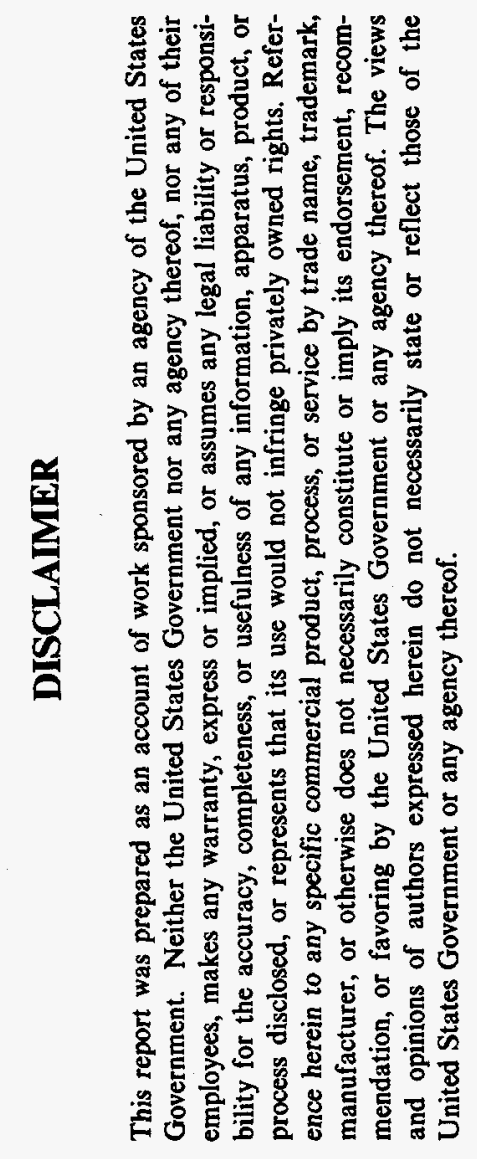

September 8, 1995

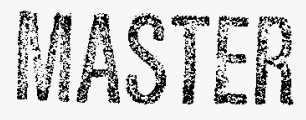

DISTRIBUTION OF THIS DOCUMENT IS UNLMITED BS

\title{
Advanced Photon Source
} Argonne National Laboratory 


\section{DISCLAMER}

Portions of this document may be illegible in electronic image products. Images are produced from the best available original document. 


\title{
HIGH-HEAT-LOAD SYNCHROTRON TESTS OF ROOM- TEMPERATURE, SILICON CRYSTAL MONOCHROMATORS AT THE CHESS F.2 WIGGLER STATION
}

\author{
W. K. Lee, P. B. Fernandez, T. Graber, and L. Assoufid \\ Experimental Facilities Division \\ Advanced Photon Source
}

\section{Introduction}

This Light Source Note summarizes the results of the single crystal monochromator high-heat-load tests performed at the CHESS F-2 wiggler station. The results from two different cooling geometries will be presented: (1) the "pin-post" crystal and (2) the "criss-cross" crystal. The data presented were taken in August 1993 (water-cooled pin-post) and in April 1995 (waterand gallium-cooled pin-post crystal and gallium-cooled criss-cross crystal).

The motivation for trying these cooling (or heat exchanger) geometries is to improve the heat transfer efficiency over that of the conventional slotted crystals. Calculations suggest that the pin-post or the microchannel design can significantly improve the thermal performance of the crystal [1]. The pinpost crystal used here was fabricated by Rocketdyne Albuquerque Operations (RAO, formerly Rockwell Power Systems). From the performance of the conventional slotted crystals, it was thought that increased turbulence in the flow pattern may also enhance the heat transfer. The criss-cross crystal was a simple attempt to achieve the increased flow turbulence. The criss-cross crystal was partly fabricated in-house (cutting, etching and polishing) and bonded by RAO.

Finally, a performance comparison among all the different room temperature silicon monochromators that have been tested by the APS will be presented. The data will include measurements with the slotted crystal and the coredrilled crystals. Altogether, the data presented here were taken at the CHESS F-2 wiggler station between 1991 and 1995.

\section{Performance of the 'original' pin-post crvstal}

Figure 1 shows the first APS prototype pin-post crystal fabricated by Rocketdyne Albuquerque Operations. The face plate of the crystal is $\mathrm{Si}(111)$. After the final assembly, the "hot-wall" thickness of the face-plate was ground down to $1 \mathrm{~mm}$. In-house double-crystal rocking curve measurements show that, over an area of $10 \times 4 \mathrm{~mm}^{2}$, the fabrication-induced strains were about 1.5 arc seconds. At that time $(-1993)$, our in-house topography station was not ready, and thus no topographs of the crystal were taken.

The first synchrotron test of this crystal took place at the F2 wiggler station at CHESS in August 1993. The experimental setup is shown in figure 2. 
Note that since the $\mathrm{x}$-ray beam from the wiggler is actually shared between the F1 and F2 stations, only half the wiggler beam (horizontally) is available in F2. Thus, the horizontal power profile of the beam in F2 is half a parabola, with the hottest part of the beam being the north side. With all the slits wide open, the total size of the beam into the station was about $40-45 \mathrm{~mm}$ horizontal and about $5 \mathrm{~mm}$ vertical. The crystal was oriented for $\theta=23.3^{\circ}$ (Si(111), $5 \mathrm{keV}$ reflection). The double-crystal monochromator sat in a tank, which was either purged with helium gas or evacuated. Aluminum filters were placed between the two ion chambers so that I1, the back ion chamber, detects the third-harmonic $15 \mathrm{keV}$ photons reflecting from the Si(333) planes. Because we do not have the luxury of changing the CESR stored beam current, the two ways to change the power and power density on the crystal are through the use of filters or changing the slit sizes. We opted to use the filters because, from our in-house measurements, we suspect that the inherent fabrication-induced strains in the crystal are area dependent. Thus, if we measured an increase in the rocking curve (RC) width from a larger beam it would be difficult to conclude if it was due to the increased heat load. The disadvantage, however, of using carbon filters to change the heat load is that it also changes the spectrum of the beam. Thus, the power absorption profile within the silicon changes depending on the amount of filters used. Figure 3 shows the calculated (PHOTON2) power and power density of the wiggler beam in F2 as a function of carbon filters at $100 \mathrm{~mA}$ ring current. For this particular run, from calorimetry, the power of the full beam in F2 was measured to be $16.6 \mathrm{~W} / \mathrm{mA}$. The estimated normal incidence peak power density at the crystal location was about $11 \mathrm{~W} / \mathrm{mm}^{2}$ at $100 \mathrm{~mA}$ ring current. Both the measured power and estimated power density are about 20-25\% lower than calculated. The cause of this discrepancy is not known.

An infrared (IR) camera was oriented to image the first crystal through a window. For the thermal-induced slope error on the crystal, the relevant quantity is the maximum temperature difference (MTD) on the crystal surface. The MTD is the difference between the peak temperature on the crystal surface and the nominal temperature of the crystal where there is no beam. The IR camera was independently calibrated with liquid gallium and water as a coolant. (A calibration is required to correct for the emissivity of silicon at these (IR) wavelengths.) In both cases, the calibration showed that the actual MTD varied approximately as: $\mathrm{MTD}_{\text {true }} \approx 1.4 \mathrm{MTD}_{\text {meas }}$, where MTD true is the true maximum temperature difference and MTD meas is the maximum temperature difference as measured by the IR camera. The difference in calibration between liquid gallium and water was less than $5 \%$. The true temperatures will be used in all the data presented in this paper.

The first tests were performed with water as the coolant. 


\section{Water cooling}

\section{Thermal (IR) measurements}

For the full wiggler beam in F2, the measured MTD on the crystal was $46^{\circ} \mathrm{C}$ at a total incident beam power of $1050 \mathrm{~W}\left(\mathrm{I}_{\text {cesr }}=63.2 \mathrm{~mA}\right)$, normal incident peak power density of about $6.9 \mathrm{~W} / \mathrm{mm}^{2}$ (surface peak power density $=2.7$ $\mathrm{W} / \mathrm{mm}^{2}$ ), and $3 \mathrm{gpm}$ water flow rate. At another power level, ( $\mathrm{I}_{\text {cesr }}=54 \mathrm{~mA}$, $2.5 \mathrm{~mm}$ carbon filter), we measured a maximum temperature difference of $29^{\circ}$ $\mathrm{C}$ at a total incident power of $645 \mathrm{~W}$ and $4 \mathrm{gpm}$ water flow rate. The estimated peak power density in this case was about $4.9 \mathrm{~W} / \mathrm{mm}^{2}$ (surface peak power density $=1.9 \mathrm{~W} / \mathrm{mm}^{2}$ ). Over the entire range of heat load, from 250-1050 W, the measured temperature difference scales more or less linearly with the heat load to within $20 \%$. Data from previous experiments and calculations suggest that, at such high MTDs, there would be noticeable slope errors on the crystal. This is verified by the rocking curve (RC) measurements.

\section{Rocking curve measurements}

Figure 4 shows the I1 intensity and widths (full beam) of the RCs as a function of carbon filters placed upstream of the monochromator. The theoretical RC width for $\mathrm{Si}(333)$ at $15 \mathrm{keV}, \mathrm{I} 1$, is 0.95 arc seconds. Clearly, the crystal shows signs of strain. The increase in width from the case of a 10 $\mathrm{mm}$ carbon filter to a $25 \mathrm{~mm}$ carbon filter is puzzling and appears to be reproducible. From the IR data, it is clear, at least for the cases with little or no carbon filters, that some of the observed strains in the crystal must be from the thermal load. However, some of the observed strains are probably fabrication or coolant-pressure induced. Because the beam footprint on the crystal here is significantly larger than those used to measure the strain inhouse, it is likely that the fabrication-induced contribution could be larger. In addition to the data shown in figure 4, the measured RC width for the case with no carbon filters and $4 \mathrm{gpm}$ water flow was 40 arc seconds at $72 \mathrm{~mA}$ ring current (1195 W).

\section{Liquid gallium cooling}

After the water measurements were done, the crystal was dried out and purged with nitrogen gas. The crystal was then connected to the liquid gallium pump. Immediately, it was obvious that the flow of liquid gallium through the crystal was severely limited. Figure 5 shows the flow characteristics. The theoretical flow characteristics were calculated by RAO. At a gallium pump driving current of $1600 \mathrm{~A}$, the flow rate through crystal was $0.3 \mathrm{gpm}$. In comparison, at this current, the slotted crystal has a flow rate of $2.4 \mathrm{gpm}$.

With such small flow rates, the crystal got too hot (peak temperature $>140^{\circ}$ C) when the full beam was used. Thus, only small beam rocking curves were 
obtained. With $2.5 \mathrm{~mm}$ carbon filters upstream and a very small beam, we reproduced the $\mathrm{RC}$ widths $(\sim 1.8$ arc sec) that we measured in-house. The strange phenomena (sometimes) of broader RC widths with more carbon filters was also observed here. In one case, the measured $\mathrm{RC}$ width was 2.7 arc seconds with $1 \mathrm{~mm}$ of carbon filter and a measured MTD of $8.4^{\circ} \mathrm{C}$, while the measured $R C$ width was 5.8 arc seconds with $10 \mathrm{~mm}$ of carbon filter and a measured MTD of $2.8^{\circ} \mathrm{C}$. One possible explanation for this unusual behaviour may be the interaction of the thermal-induced strains with the fabrication/coolant-pressure-induced strains.

\section{Modification of the pin-post crystal}

The gallium flow characteristics of the pin-post crystal were very puzzling. Since it was not understood why the gallium did not flow well across the pinpost crystal, it was decided that test pieces with pin-post cells of various dimensions be fabricated and tested at ANL before deciding how much to open up the pin-post dimensions. Several such tests were performed. The results were then used to modify the original pin-post crystal. For the modified crystal, the height of the posts was increased from 0.010 " to 0.030 ". In addition, the inlet and outlet distribution holes were chamfered. The "hotwall" thickness of the top-plate remained the same at $\sim 1 \mathrm{~mm}$.

\section{Performance of the 'new' pin-post crystal}

In-house topography measurements were performed on the new pin-post crystal (with no coolant flow) and a typical topograph, taken at $8 \mathrm{keV}$, is shown in figure 6 . The corresponding $\mathrm{RC}$ measurements show that there was about 3.8" fabrication-induced strain over the entire 4 inch diameter face of the crystal. The strain is dependant on the size of the sampled area; over an area of about 1 square inch, the measured strain was about 2.6". The topographs clearly show the underlying pin-post cell structure. Obviously, there is much room for improvement in the fabrication/bonding procedure.

The 'new' or modified pin-post crystal with its wider channels was tested at the F2 wiggler station at CHESS in April 1995. The first tests were performed using water as the coolant. The experimental setup is similar to that shown in figure 2. In this case, the crystals were oriented to $\theta=14.31^{\circ}$, corresponding to $8 \mathrm{keV}$ reflection for the $\mathrm{Si}(111)$. Between the two ion chambers, I0 and I1, was 0.125 inches of aluminum. Thus, the back ion chamber, I1, detects the third harmonic $24 \mathrm{keV}$ photons reflecting from the $\mathrm{Si}(333)$ planes. From calorimetry, the power of the full beam in F2 was measured to be $18.4 \mathrm{~W} / \mathrm{mA}$. The measured power per milliamp ring current is larger than in previous runs by about $10 \%$ and is closer to the theoretical value. The estimated normal incidence peak power density at the crystal location was $14.5 \mathrm{~W} / \mathrm{mm}^{2}$. 
Water cooling

\section{Thermal (IR) measurements}

From the IR camera, we obtained the temperatures on the surface of the crystal. Figures 7,8, and 9 show the variation in the temperature on the crystal surface as a function of water flow rate for the case of $5 \mathrm{~mm}$ of carbon filter, $2.5 \mathrm{~mm}$ of carbon filter, and no carbon filter. The data suggest that more flow was needed to reduce the crystal temperatures. Unfortunately, we were not able to increase the flow rate due to limitations of the water pump. The MTDs measured here are generally lower than those measured for the original pin-post crystal. This is somewhat surprising because, for a given flow rate, the actual coolant flow velocity in the pin-post cell should be 3 times lower here due to the increased post height.

\section{Rocking curve measurements}

Figure 10 shows the measured I1 intensity (normalized to the ring current), with the associated width of the double-crystal $\mathrm{RC}$ as a function of carbon filters inserted upstream of the monochromator. The water flow rate was set at $3.75 \mathrm{gpm}$. The measurement was repeated 24 hours later, as shown in figure 11. The variation of the $\mathrm{RC}$ widths with carbon filters are puzzling and are reminiscent of the original crystal (figure 4). Attempts to obtain RC widths that were more consistent with those measured in-house were not successful. Closing the horizontal slits to get a smaller and cooler beam on the crystal sometimes reduced the width of the RC. At best, with about 1/4 the total beam size and $25 \mathrm{~mm}$ of carbon filter in the beam, the measured full beam RC width was 5.2". In other cases, even reducing the beam size further ( $1 / 10$ of the full beam) gave RC widths of about 11". Overall, the measured $\mathrm{RC}$ trends in the modified pin-post crystal are more or less similar to the original crystal, although the measured widths here are consistently narrower for the same conditions. For example, the measured RC width for the case with no carbon filters for the new pin-post crystal was $\sim 13$ arc seconds with $3.75 \mathrm{gpm}$ flow and $\sim 1932 \mathrm{~W}$ total power compared to $\sim 40$ arc seconds with $4 \mathrm{gpm}$ water flow and $\sim 1195 \mathrm{~W}$ for the original crystal. As with the IR data, this improved performance over the original crystal is puzzling and not consistent with the actual coolant flow velocity in the pin-post cells.

\section{Liquid-gallium cooling}

\section{Thermal (IR) measurements}

Due to the failure of the original IR camera (Inframetrics model 760), a different IR camera (FSI model IQ 812) was used in this set of measurements. Prior to taking data, the camera was also calibrated. The calibration was the same as for the Inframetrics camera. Figure 12 shows the crystal surface MTDs as a function of the carbon filter used, for a $2 \mathrm{gpm}$ 
gallium flow rate. The average ring current during this measurement was $130 \mathrm{~mA}$. As expected, the MTDs decrease with increasing carbon filters. Figure 13 shows the crystal surface MTDs as a function of the gallium flow rate for the case with a $5 \mathrm{~mm}$ carbon filter upstream. The average ring current here was $107 \mathrm{~mA}$. A comparison between figure 13 and figure 7 clearly shows that the crystal performed much better with water than with liquid gallium. This was totally unexpected. One possible explanation is that a few of the cells are blocked and thus, local hot spots occur on the crystal. This would be somewhat consistent with the IR images where, depending on where the beam hits the crystal, local hot spots sometimes appear. However, because the gallium seems to flow reasonably well (see below) through the crystal, the number of such blocked cells, if any, must be relatively small.

\section{Rocking curve measurements}

Figure 14 shows the variation of the intensity and widths of the RCs as a function of carbon filter thickness for a gallium flow rate of $2.15 \mathrm{gpm}$. Even with the maximum amount of carbon filters, the crystal is highly strained. The best $\mathrm{RC}$ width measured was about 13 arc seconds. Comparing figures 14 and 10 , the RC data show that the water-cooled crystal consistently out performs the gallium-cooled crystal. While this is consistent with the IR data, it is contrary to what is expected.

\section{Liquid-gallium flow characteristics}

Due to the difficulty in getting liquid gallium to flow in the original pin-post crystal, measurements were made to characterize the liquid-gallium flow in this modified pin-post crystal. Figure 15 shows the measured pressure drop across the crystal. From the figure, we see that the pressure drop here for a $2.5 \mathrm{gpm}$ flow is about $35 \mathrm{psi}$. For comparison, the pressure drop for a similar setup and flow rate for a slotted crystal is about 5 psi.

\section{Some conclusions regarding the pin-post crystal measurements}

These tests show that, with the available coolant flow rates and at these heat loads, the pin-post crystal did not perform well. There were also several puzzling observations: (1) the strange variation of the $\mathrm{RC}$ widths with the heat load (figures 4, 10, and 11), (2) the new pin-post crystal seems to perform better than the original crystal despite the fact that the actual cell flow velocity of the new crystal is 3 times smaller and (3) the poor performance of the crystal with liquid gallium. The fabrication- and coolant-pressureinduced strains and their interaction with the thermal-induced strains could be a factor in (1). The IR images suggest that blocked cells, causing local hot spots, may be the cause of (3). From the topograph of the crystal, it is clear that the crystal fabrication/bonding process needs to be improved. 


\section{Performance of a criss-cross natterned crvstal}

In an attempt to improve the heat transfer capabilities of the slotted crystal geometry, a criss-cross patterned crystal was fabricated. The idea here being that the criss-cross pattern would increase the flow turbulence and thus would improve heat transfer. If it worked, it would be equivalent to a "poorman's" pin-post crystal (assuming the pin-post crystal worked). Figure 16a shows a sketch of the criss-cross cooling geometry.

In-house topography and $\mathrm{RC}$ measurements show that the fabricationinduced strain on the crystal was about 2.5 arc seconds in one orientation and about 5 arc seconds $90^{\circ}$ away. For the synchrotron measurements, the crystal was oriented so that the effect of the strain was minimized in the scattering plane. Figure $16 \mathrm{~b}$ shows a topograph of the crystal taken at 8 $\mathrm{keV}$. Although not as prominent as the pin-post crystal, the criss-cross pattern is clearly visible.

The criss-cross patterned crystal was tested at the F-2 wiggler station at CHESS in April 1995 (the same run as the 'new' pin-post crystal). The crystals were oriented to $\theta=14.31^{\circ}$, corresponding to $8 \mathrm{keV}$ reflection for the $\mathrm{Si}$ (111) Bragg planes. Between the two ion chambers, I0 and I1, was 0.125 inches of aluminum. Thus, the back ion chamber, I1, detects the third harmonic $24 \mathrm{keV}$ photons reflecting from the $\mathrm{Si}(333)$ planes. From calorimetry, the power of the full beam in F2 was measured to be $18.4 \mathrm{~W} / \mathrm{mA}$. The estimated normal incidence peak power density at the crystal location was $14.5 \mathrm{~W} / \mathrm{mm}^{2}$.

\section{Thermal (IR) measurements}

The setup of the experiment is similar to that described above. Due to time constraints, the experiment was only performed with liquid gallium as the coolant. Figures 17-19 show the surface MTD of the crystal as a function of flow rate for the case of $5 \mathrm{~mm}$ of carbon filter, $2.5 \mathrm{~mm}$ of carbon filter, and no filter, respectively. The temperature variations are as expected. In all three cases, the MTD on the surface appears to level off between 2 and $2.5 \mathrm{gpm}$. This suggests that increasing the flow rate will not substantially decrease the surface temperatures.

\section{Rocking curve measurements}

Figure 20 shows the RC data as a function of carbon filter thickness for a gallium flow rate of $1.01 \mathrm{gpm}$, at an average ring current of $116 \mathrm{~mA}$. The widths of the RCs decrease with increasing amount of carbon filters, as expected. Figure 21 shows the RC data as a function of the gallium flow rate. Figure 22 shows the variation of the RC as a function of liquid-gallium flow rate with $25 \mathrm{~mm}$ of carbon filters upstream of the monochromator. With such a small heat load, we see that the widths of the RCs are consistent with the 
in-house values. The leveling off of the $\mathrm{RC}$ widths in this case also suggest that there is no evidence of flow-induced vibrations; at least none is detected at the $2-3$ arc second level.

\section{Liquid-gallium flow characteristics}

Figure 23 shows the variation of pressure with flow rate at various points of the coolant loop. For a flow rate of $2.5 \mathrm{gpm}$, the pressure drop across the crystal was 50 psi. The pressure drop across the crystal was larger than that of the pin-post crystal. This is surprising because the coolant channels in the criss-cross crystal are the same size as the slotted crystal and are generally larger than those of the pin-post crystal. Given the limitations of the gallium pump head pressure, the pressure drop across the crystal clearly limits the maximum flow rate through the crystal.

\section{General conclusions and comparison with the pin-post crystal}

Clearly, the criss-cross crystal did not perform well under conditions of full beam and no filter ( $\sim 140 \mathrm{~mA} \times 18.4 \mathrm{~W} / \mathrm{mA}=2576 \mathrm{~W}$ total power, $5.0 \mathrm{~W} / \mathrm{mm}^{2}$ peak surface power density). Since the gallium cooled pin-post crystal clearly had some unknown problems, it is perhaps better to compare the watercooled pin-post crystal with the gallium-cooled criss-cross crystal. Comparing the IR data in figures 9 and 19, for the same flow rate, the MTD for the gallium-cooled criss-cross crystal is consistently lower than that for the water-cooled pin-post crystal. For example, the MTD for the criss-cross crystal at $2 \mathrm{gpm}$ liquid-gallium flow rate is about $19^{\circ} \mathrm{C}$, while that for the pin-post crystal with $2 \mathrm{gpm}$ water flow is about $41^{\circ} \mathrm{C}$, at roughly the same heat load conditions (full beam, no carbon filters, $I_{\text {cesr }} \sim 112 \mathrm{~mA}$ ). Even at the maximum water flow rate of $3.75 \mathrm{gpm}$, the MTD for the pin-post crystal was about $30^{\circ} \mathrm{C}$. Unfortunately, no $\mathrm{RC}$ data was available for the two crystals under similar coolant flow rate and heat load for comparison.

\section{Comparisons of different cooling geometries}

The impetus for trying the pin-post and criss-cross geometries was to investigate the possibility of improving the heat transfer from the crystal to the coolant. The hope was that these more sophisticated geometries would be significantly better than the conventional slotted geometry. Thus, it is useful to compare the measured performances of these different heat exchanger geometries. Ideally, in order to make a fair comparison between the different geometries, the experiments should be performed with identical parameters, such as the thickness of the top-plate, the heat load, the coolant, and the flow rate. Unfortunately, this was not true here due to the slightly different experimental conditions for each high-heat-load crystal test. For example, sometimes the experiments were performed at $5 \mathrm{keV}$ and at other times at 8 or $11 \mathrm{keV}$, thus changing the heat load spreading factor on the crystal surface. Some runs were done with liquid gallium as a coolant, while others had water as a coolant. Also, the maximum ring current at CHESS varied 
between $70 \mathrm{~mA}$ to $150 \mathrm{~mA}$ for the different runs. It would be preferable to compare the amount of thermal-induced strains in each of the tests.

However, due to the different fabrication and/or pressure-induced strains in the crystals, and, as a result, the difficulty in extracting the thermal-induced strains from the RC data, we chose to compare the IR thermal data (MTD) instead.

Because it was not clear how the temperature scales with the heat load (i.e., with power or power density), we did the comparisons for two different cases: (1) by scaling the temperatures with total power and (2) by scaling the temperatures with surface peak power density. Because all the tests were performed at the F2 wiggler station at CHESS, we did not consider any differences in the absorbed power profile within the crystals. All the crystals had a "top-plate" or "hot-wall" thickness of about $1 \mathrm{~mm}+/-20 \%$, and, thus, the actual absorbed power in the crystal should be more or less the same. In terms of coolant flow rates, as far as possible, all the data presented below are for $2 \mathrm{gpm}$ coolant flow.

Due to the different system parameters during these measurements, admittedly, such comparisons are very limited in scope. In no way are they rigorous, fair, or complete. In spite of the difficulties involved, it is hoped that any significant advantage of one system or geometry over the next could be evident. We emphasize that the results of the following comparisons are to be taken in context of the experimental parameters. Figure 24 shows the two other geometries to be discussed, namely, the slotted crystal and the coredrilled crystal.

The comparisons shall be presented in two ways. The first presents the data (figure 25 and 26) with more or less constant flow rate, linearly scaled to a constant heat load, but with different coolants. This method of comparison would provide a simple direct comparison of the tests that have been performed so far. The only scaling here involves the heat load; all the MTDs were scaled (linearly) to a constant total power of $1000 \mathrm{~W}$ (figure 25) or a constant surface power density of $3.6 \mathrm{~W} / \mathrm{mm}^{2}$ (figure 26). As far as possible, the data shown are for a coolant flow rate of $2 \mathrm{gpm}$. For example, the MTD on the criss-cross crystal was $19.2^{\circ} \mathrm{C}$ at $108.7 \mathrm{~mA} \mathrm{CESR}$ ring current. In this case, the measured power was $18.4 \mathrm{~W} / \mathrm{mA}$, and a normal incidence peak power density at the crystal location was $0.145 \mathrm{~W} / \mathrm{mm}^{2}-\mathrm{mA}$. Thus, when scaled to $1000 \mathrm{~W}$ total power, the MTD $=19.2 \times 1000 /(108.7 \times 18.4)=9.6^{\circ} \mathrm{C}$. Similarly, since the crystal was oriented at $\theta=14.31^{\circ}$, when scaled to 3.6 $\mathrm{W} / \mathrm{mm}^{2}$ surface power density, the MTD $=19.2 \times 3.6 /(108.7 \times 0.145 \times \sin$ $\left.14.31^{\circ}\right)=17.7^{\circ} \mathrm{C}$.

The second set of data (figures 27 and 28) presented has a constant flow rate (more or less) and the MTD scaled to a constant heat load and to water as a coolant. This method of comparison attempts to reveal the differences in the geometries. In order to make this second comparison, it is necessary to scale to the heat load and to the differences between liquid gallium and water. 
Here, the assumption is that the $\mathrm{MTD}_{\text {water }} \approx 3 \mathrm{MTD}$ gallium. This assumption comes from past empirical observations. Theoretical calculations $[2,3]$

suggest that, depending on the actual geometry, $\mathrm{MTD}_{\text {water }} \approx 1.5-2.5$

MTD gallium. Thus, for example, in figure 26, the MTD for the liquid-galliumcooled slotted crystal ranges from $4-7^{\circ} \mathrm{C}$. We assume then, that if water were used as a coolant instead, the MTD ranges would be from $12-21^{\circ} \mathrm{C}$, as shown in figure 27.

Figures 25-28 clearly show that the liquid-gallium-cooled slotted crystal monochromator had the best performance. In fact, figures 27 and 28 suggest that, at similar coolant flow rates, slotted geometry is better than all the other geometries considered here, including the pin-post. This is rather surprising, because the pin-post cell design was suppose to have significantly better heat transfer between the crystal and the coolant. Clearly, from the data considered here, there is no evidence that the pin-post geometry is better than the slotted geometry. Similarly, the criss-cross crystal did not perform as expected. The increased flow turbulence did not appear to improve its performance. In fact, the data shows that the criss-cross crystal is inferior to the slotted crystal.

The comparisons above were based on similar flow rates for the different crystals. While such constant flow rate comparisons may be more practical, it may not be fair since it is the actual coolant flow velocity that governs the heat transfer. Table I shows the estimated flow velocity for the particular crystals considered here for a uniform $1 \mathrm{gpm}$ flow into and out of the crystal. The table shows large differences between the flow velocities for the different geometries.

Table I: Flow velocities through the coolant channels of different crystals for an overall flow rate of $1 \mathrm{gpm}$.

\begin{tabular}{|c|c|}
\hline Crystal & $\begin{array}{c}\text { Flow velocity (cm/sec) - for an overall } \\
\text { flow rate of } 1 \mathrm{gpm}\end{array}$ \\
\hline 11-hole, core-drilled crystal & 126 \\
\hline Slotted crystal & 63 \\
\hline Original pin-post crystal & 30 \\
\hline New (modified) pin-post crystal & 10 \\
\hline
\end{tabular}

In view of this, a final comparison can be made between the slotted geometry and the pin-post geometry. Figure 29 shows the MTDs for the slotted crystal and the pin-post crystal as a function of actual coolant velocity. The data presented here were scaled to $3.6 \mathrm{~W} / \mathrm{mm}^{2}$ surface power density. This figure explains the reason for the observed poor performance of the pin-post crystal in figures 25-28. In figures 25-28, the comparisons were for a constant flow rate of $2 \mathrm{gpm}$. However, this translates into a flow velocity of $20 \mathrm{~cm} / \mathrm{sec}$ for the pin-post crystal and $120 \mathrm{~cm} / \mathrm{sec}$ for the slotted crystal! Thus, the poor performance of the pin-post crystal. In fact, figure 29 shows that at similar 
flow velocities, the pin-post geometry may be $\sim 1.6$ times better (in the MTD) than the slotted geometry. It is interesting to note that this is about half the advantage in going from water to gallium.

A related explanation for the poor pin-post crystal performance may be the amount of coolant flow under the hottest part of the crystal. Suppose the "hottest" part of the beam is about $1 \mathrm{~mm} \mathrm{x} 1 \mathrm{~mm}$ normal incidence. At a Bragg angle of $14.3^{\circ}$, this will spread out to about $1 \mathrm{~mm} \times 4 \mathrm{~mm}$ on the crystal surface. Given that the size of each cell in the pin-post design is 2.54 $\mathrm{mm} \times 2.54 \mathrm{~mm}$, this means that only about 2 cells were involved in the cooling of the crystal hot-spot. There were a total of 676 cells in the pin-post crystal (cooled area of $2.6^{\prime \prime} \times 2.6$ "). Thus, of the total coolant flow, only about $1 / 338$ of the flow was utilized in cooling the hottest part of the crystal. By comparison, for the slotted crystal, where the slots and ribs were about $1 \mathrm{~mm}$ wide, the crystal hot-spot covers about 1 slot. But given that there are usually only about 34 slots (average) in the crystal, the fraction of coolant directly involved in cooling the hot spot is $1 / 34$. This is about 10 times better than the pin-post crystal.

Admittedly, the above comparisons are not completely rigorous. The conclusions here about the performance of the crystals must be taken in context of the experimental parameters. Given the power profile of the CHESS F2 wiggler beam and the amount of coolant flow (water or liquid gallium) available in our experiments, the pin-post crystal clearly did not perform as well as the slotted crystal. However, figure 29 suggests that the poor performance of the pin-post crystal was due to insufficient coolant flow. In fact, the figure suggests, at similar flow velocities, the pin-post geometry would be superior to that of the slotted geometry. This would be consistent with the theory. With the present pin-post geometry, water flow rates of up to $12 \mathrm{gpm}$ (yielding $120 \mathrm{~cm} / \mathrm{sec}$ flow velocity) may be necessary for good performance. An alternative to the high flow rates would be to try to reduce the cooled surface area, thus reducing the amount of flow necessary for a particular flow velocity. Finally, we note that the measured performance of the water cooled pin-post crystal is consistent with that of the pin-post crystal tested by Arthur et al. [4]. 


\section{Summary}

In summary, of the different types of room temperature cooling geometries and coolants used in high-heat-load single-crystal monochromators tested at the CHESS wiggler beams, the liquid-gallium-cooled slotted crystal gave the best performance. However, there is evidence which suggests that for the same flow velocity, the pin-post geometry appears to have an advantage over the slotted geometry. With the present crystals, the flow velocity of the pinpost crystal is 6 times less than that of the slotted crystal for the same overall coolant flow rate. It is for this reason that, when comparisons with constant flow rates are done, the pin-post geometry did not reveal itself to be better. The disadvantage of the current pin-post crystal clearly is that, at the heat loads considered here, it requires a relatively large coolant flow (>10 gpm) for acceptable performance.

Acknowledgements

The authors would like to thank the people who were involved in the previous (1991-1994) high heat load experiments - Robert Smither, Shawn Rogers, Albert Macrander and Denny Mills. All the experiments discussed here would not have been possible if not for the outstanding assistance of the CHESS staff. This work is supported by the U.S. Department of Energy, Office of Basic Energy Science, under contract No. W-31-109-ENG-38.

\section{References}

1. R. Wahl, R. Shah, K. Jackson and T. Tonnessen, Nucl. Instrum. and Meth. A318, 908-913 (1992).

2. D. M. Mills, A. M. Khounsary, J. Chrzas and P. J. Viccaro, Workshop on High Heat Load X-ray Optics, Argonne National Laboratory, August 1989. Argonne National Laboratory publication ANL/APS/TM-6.

3. D. Bilderback and Q. Shen, Workshop on High Heat Load X-ray Optics, Argonne National Laboratory, August 1989. Argonne National Laboratory publication ANL/APS/TM-6.

4. J. Arthur, W. H. Tompkins, C. Troxel, Jr., R. J. Cantolini, E. Schmitt, D. H. Bilderback, C. Henderson, J. White, and T. Settersten, Rev. Sci. Instrum., $63,433-436,(1992)$. 


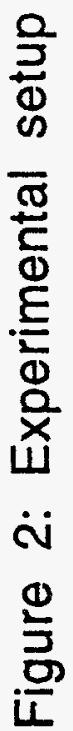

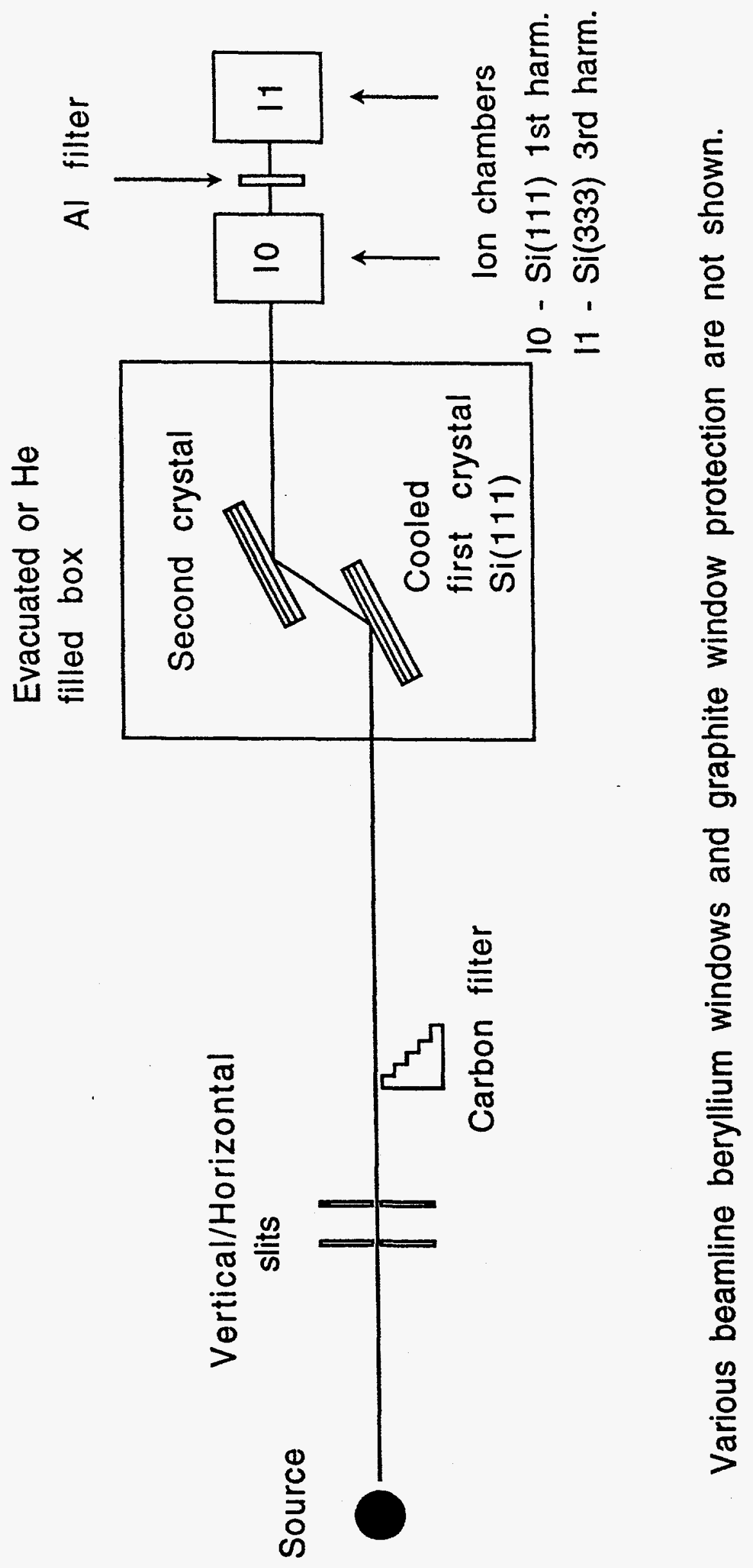


Figure 3: Calculated power and power densities for $I_{\text {cesr }}=100 \mathrm{~mA}$ at the CHESS F-2 station (at the crystal location, $\sim 26 \mathrm{~m}$ from the wiggler) as a function of carbon filter thickness.

The calculations include absorption from the beryllium windows $(0.048$ " beamline Be windows $+0.010^{\prime \prime}$ DCM tank Be window $+0.010^{\prime \prime}$ graphite window protector)

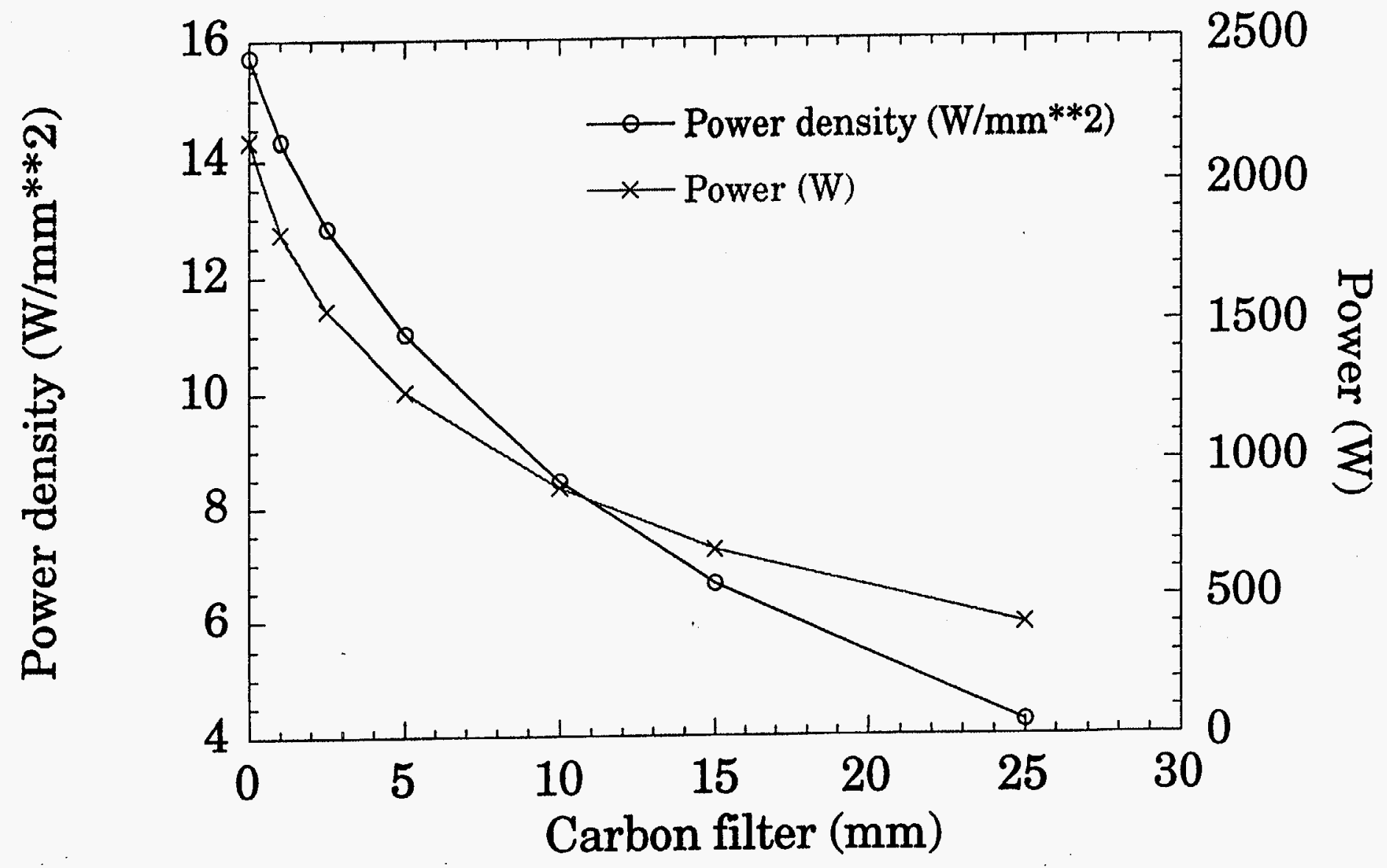


Figure 4: Full beam II intensity and RC width for the original pin-post crystal as a function of carbon filter thickness. Water flow rate was $4 \mathrm{gpm}$.

Average current $=59 \mathrm{~mA}(16.6 \mathrm{~W} / \mathrm{ma}), \mathrm{Si}(111), \theta=23.3^{\circ}, 0.03125^{\prime \prime} \mathrm{Al}$ between $\mathrm{I} 0$ and $\mathrm{I} 1$

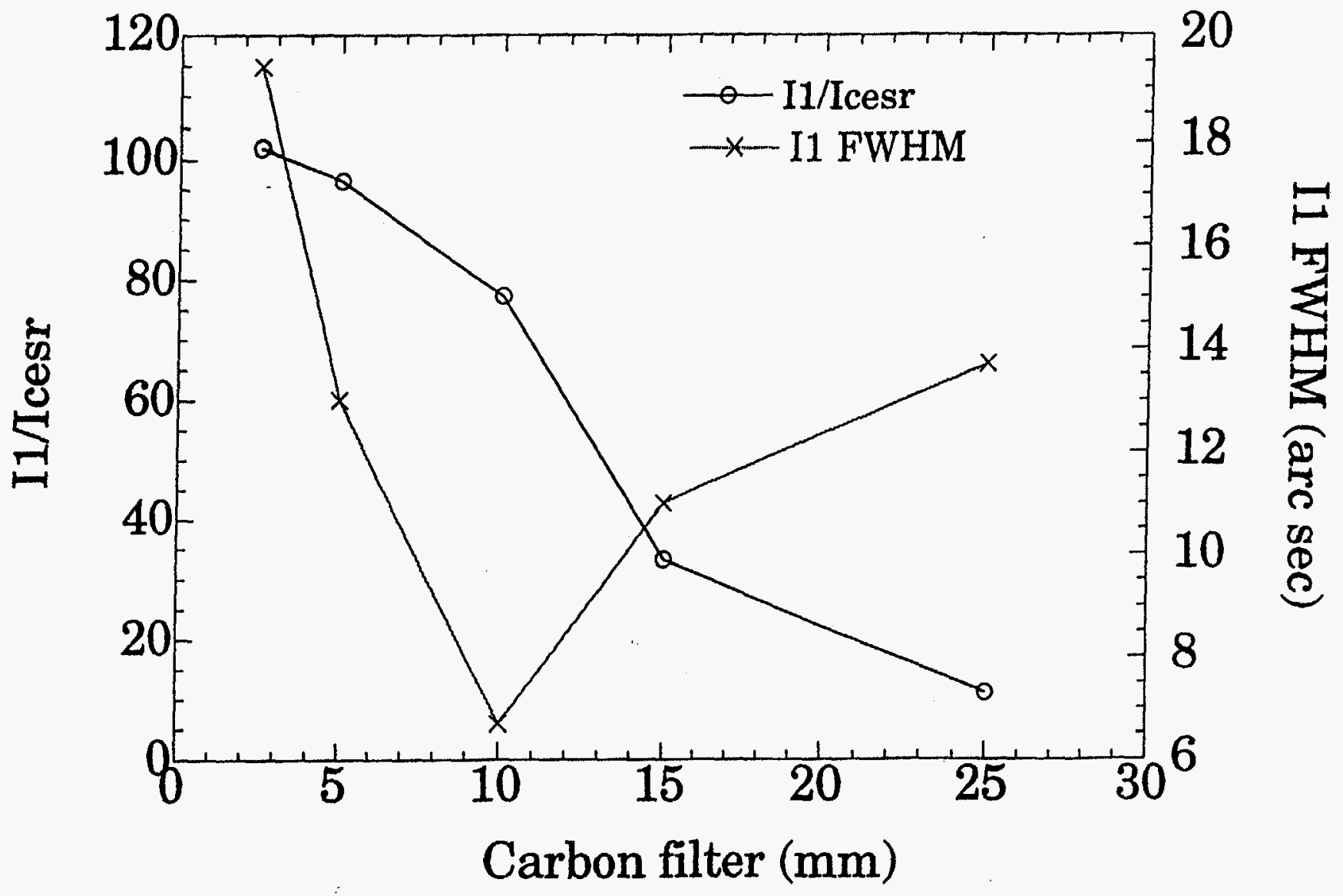


Figure 5: Liquid gallium flow characteristics of the original pin-post crystal

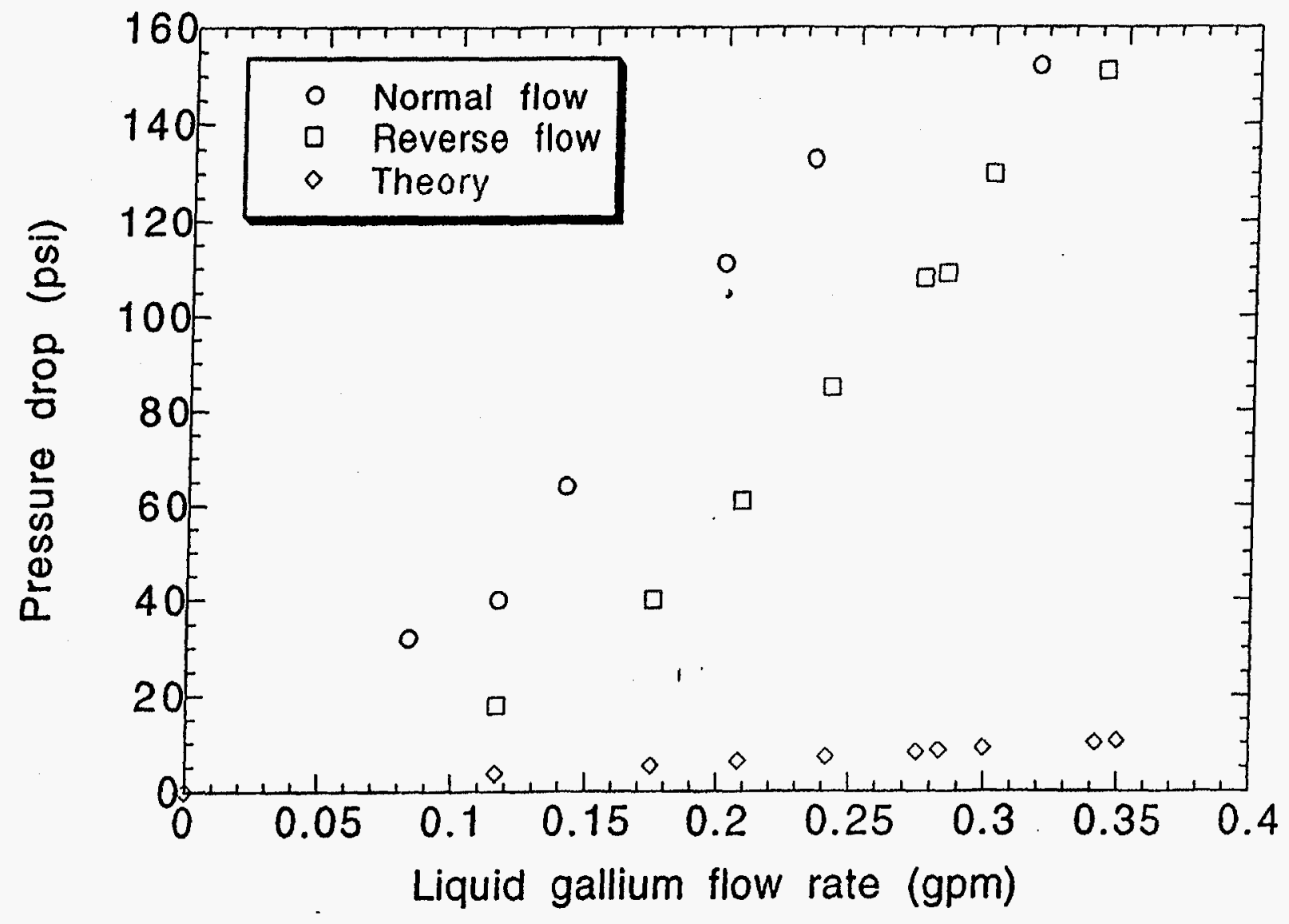




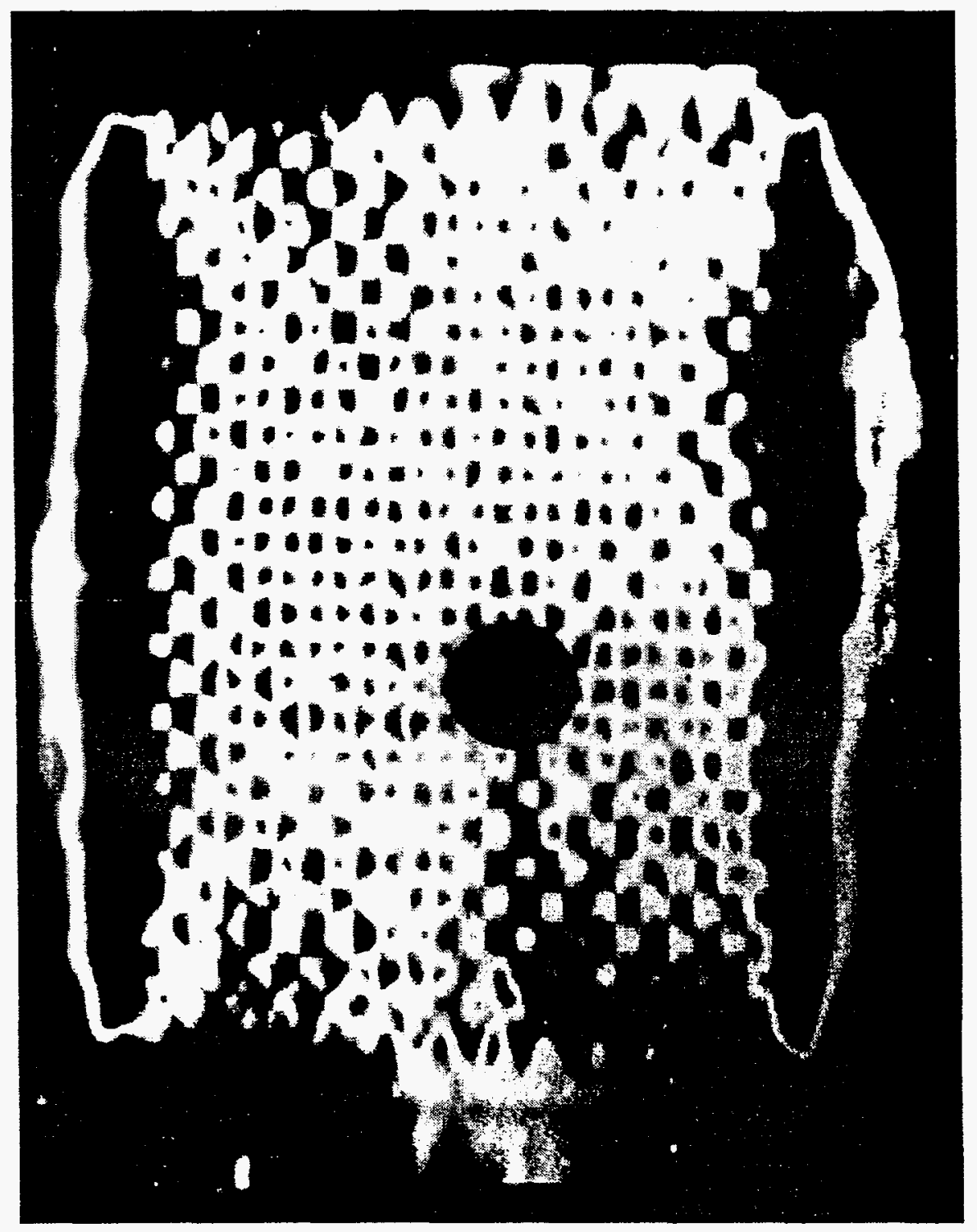

Figure 6: 8-keV topograph of the modified pin-post crystal. The central dark circular spot is an artifact from the film cassette. As a scale, the diameter of the spot is $3 / 8$ inch. Note that the topograph of the crystal is slightly compressed in the horizontal direction due to the Bragg angle. 


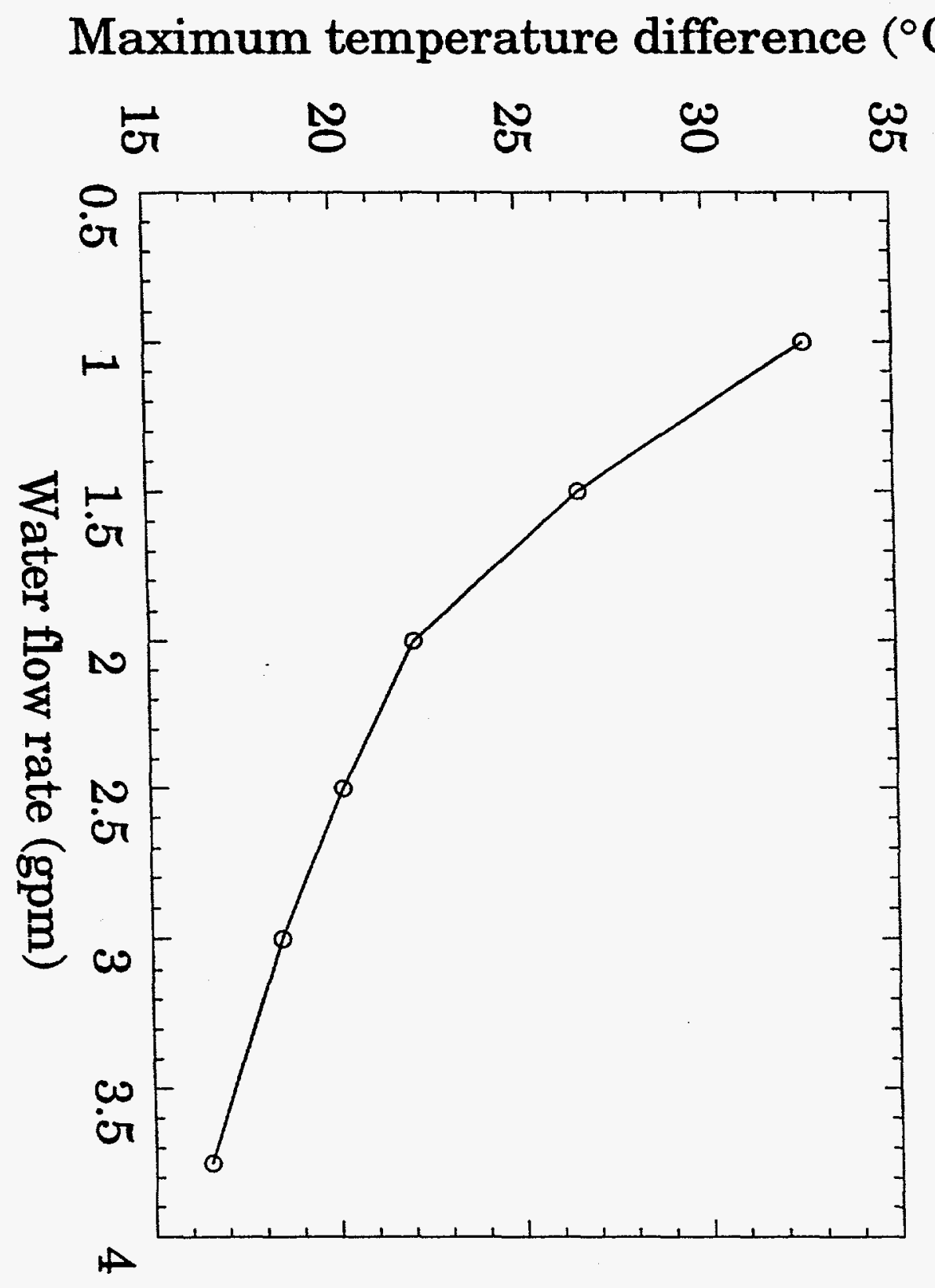

) 


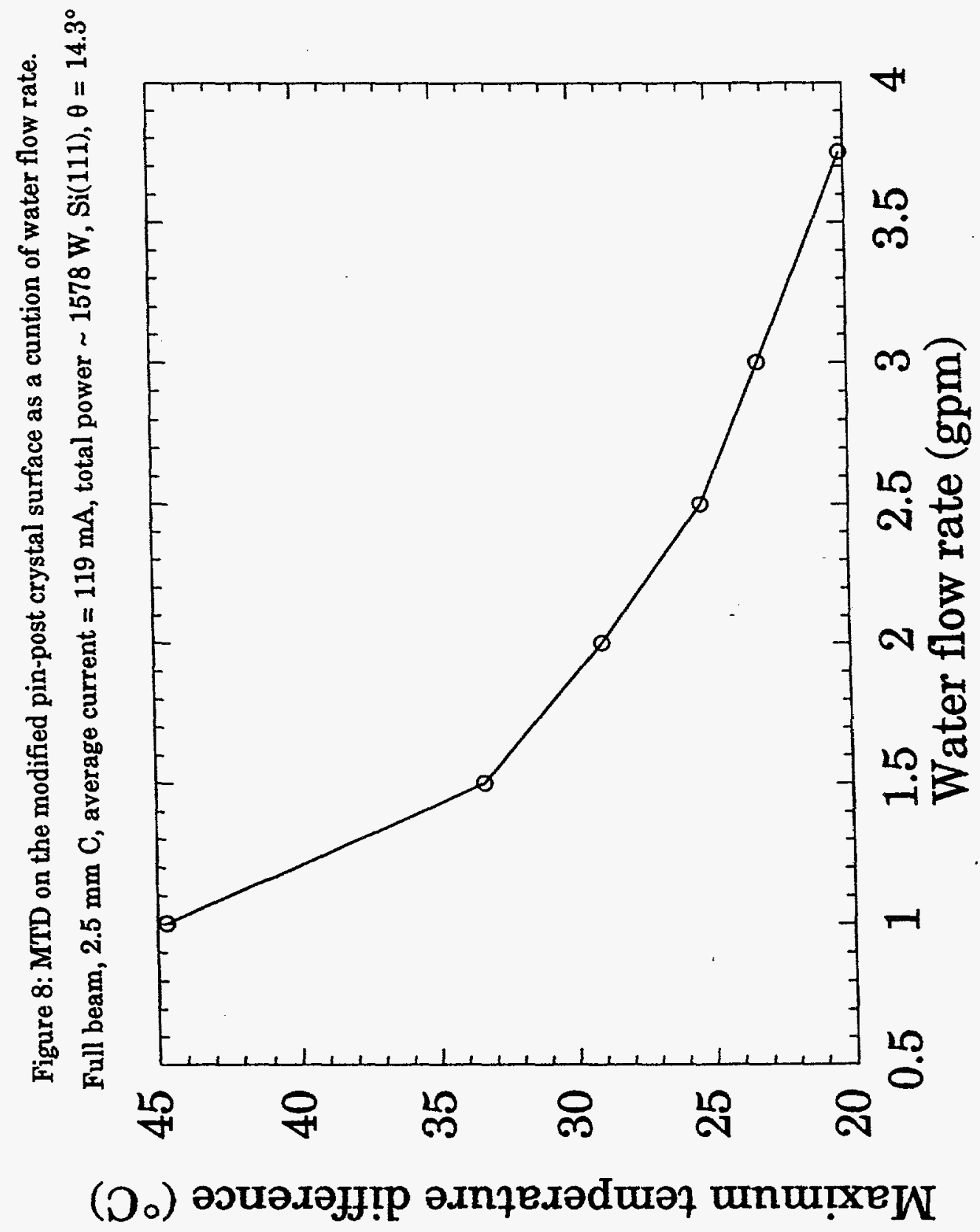




\section{Maximum temperature difference $\left({ }^{\circ} \mathrm{C}\right)$}

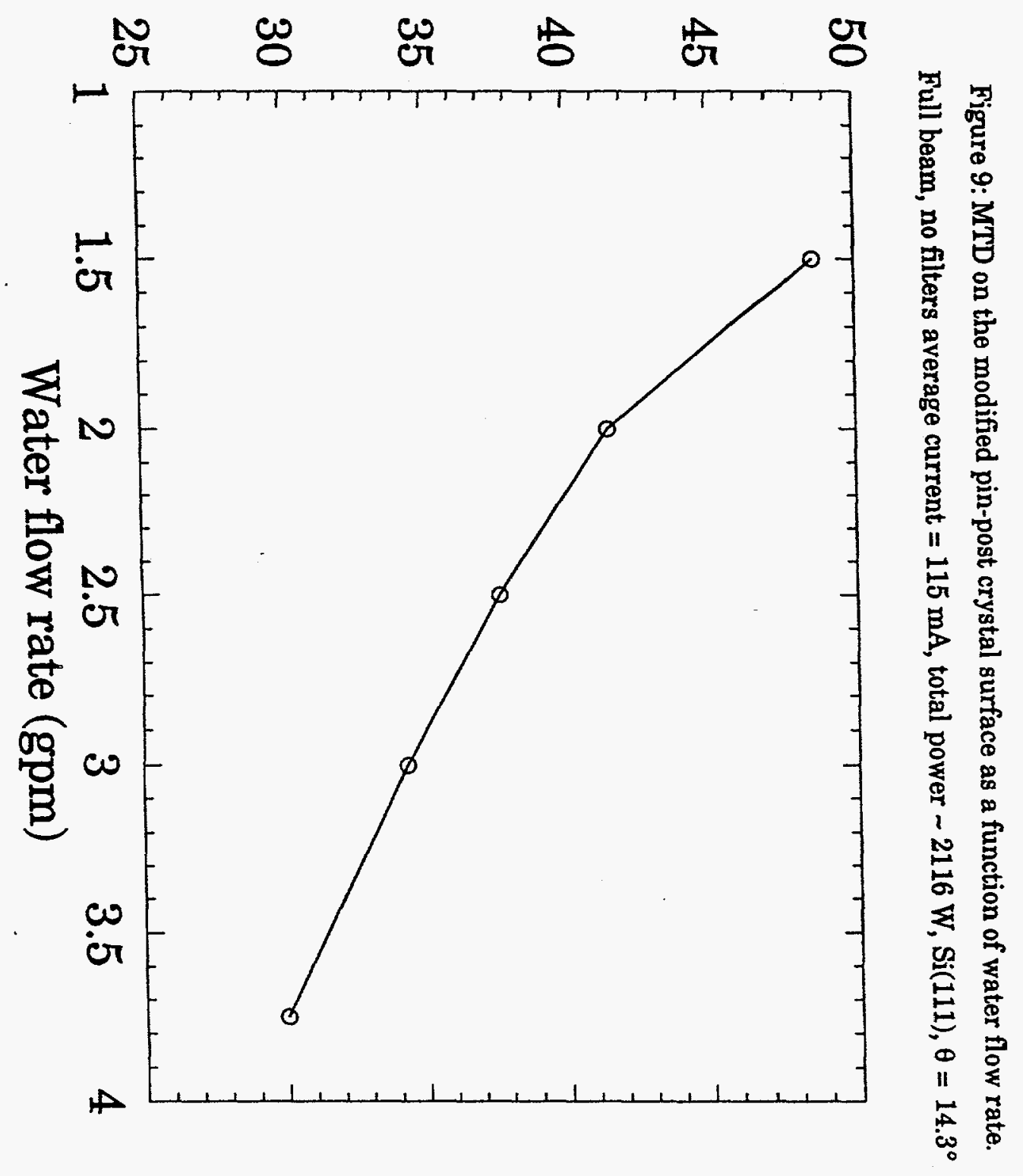


Figure 10: I1 intensity and RC width for the modified pin-post crystal as a function of carbon filter thickness Full beam, average current $=113 \mathrm{~mA}, 3.75 \mathrm{gpm}$ water flow, $\mathrm{Si}(111), \theta=14.3^{\circ}, 0.0125^{\prime \prime} \mathrm{Al}$ between $\mathrm{I0}$ and I1.

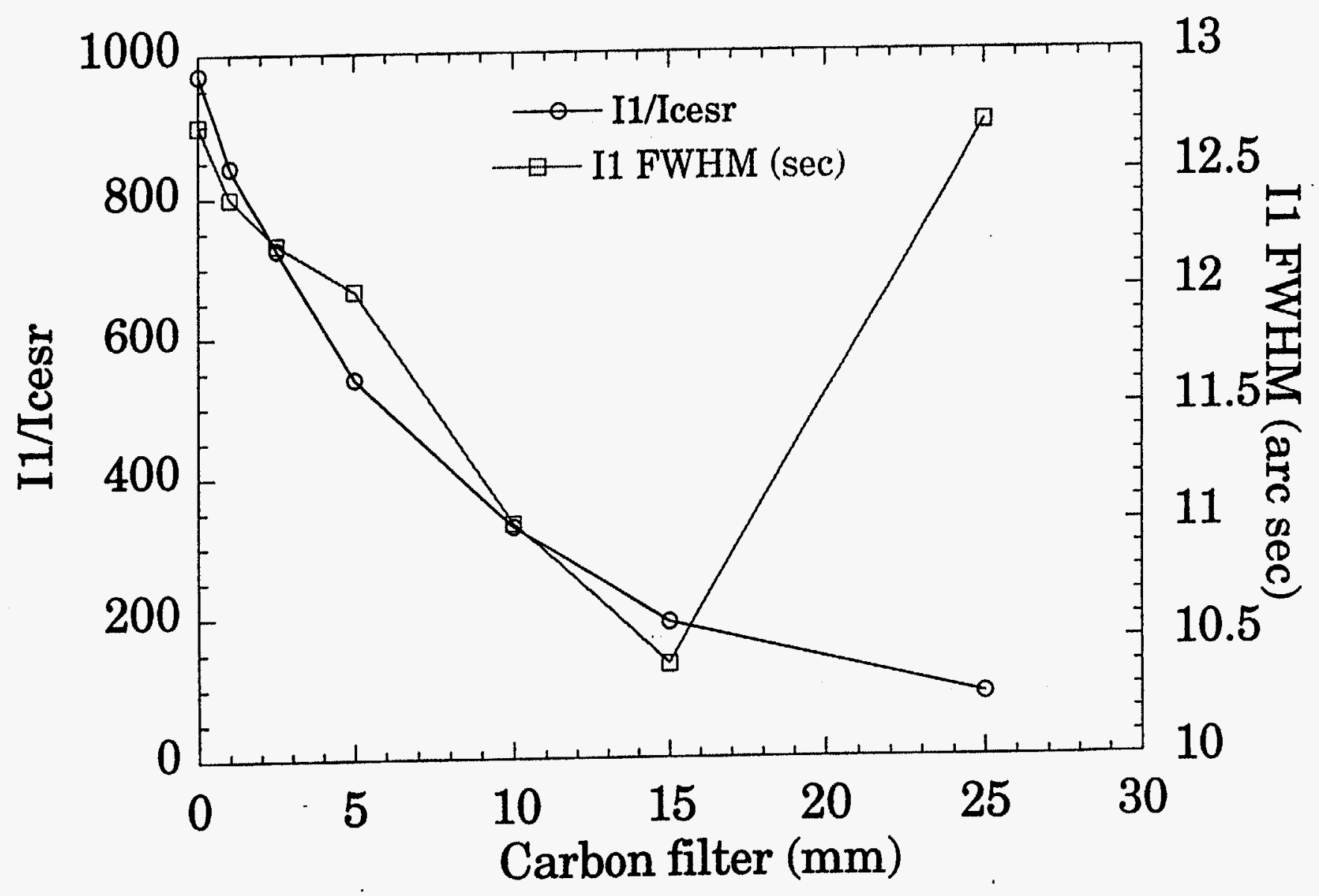




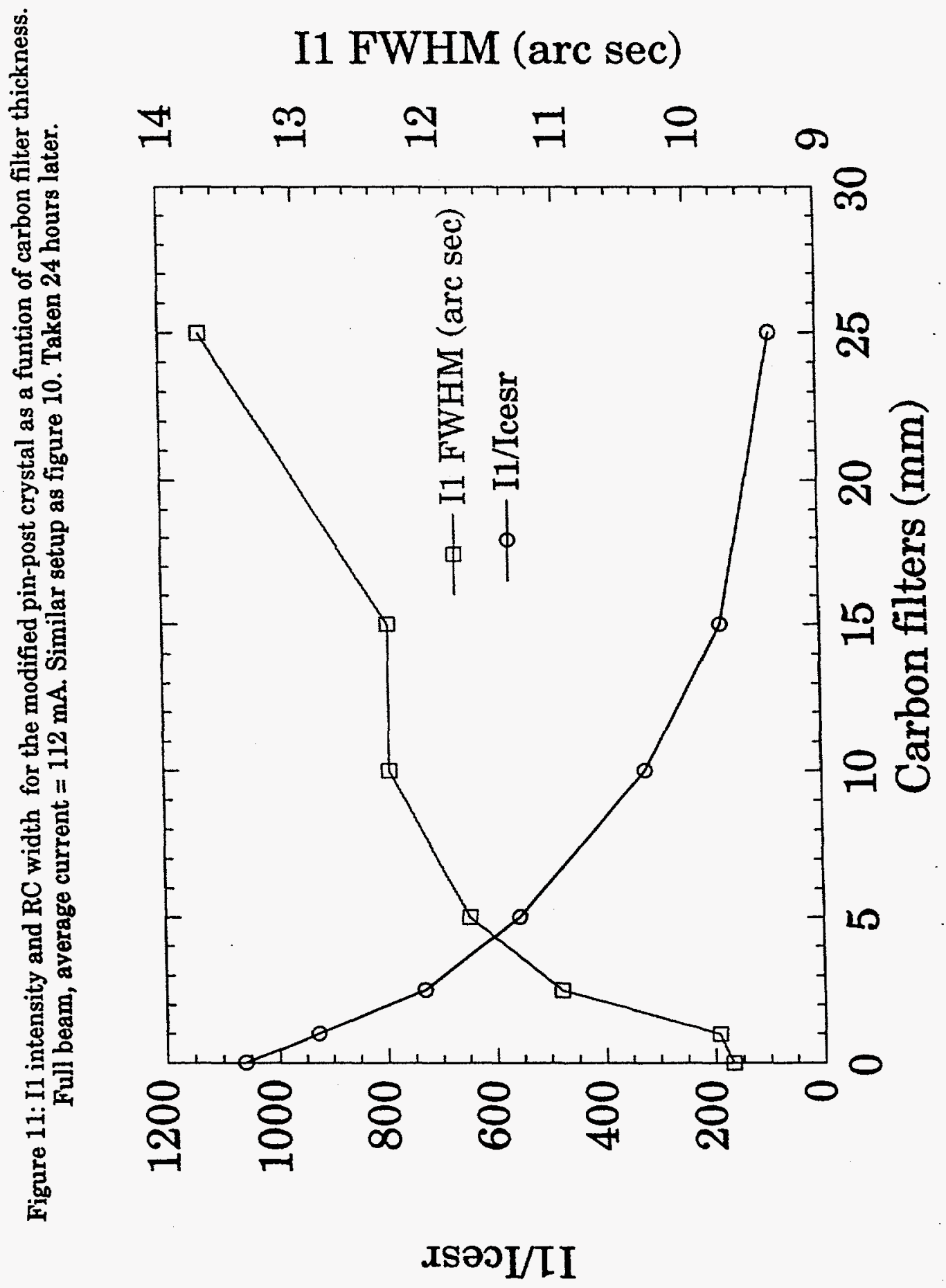


Figure 12: MTD on the modified pin-post crystal surface as a function of carbon filter thickness. Full beam, average $I_{\text {cear }}=130 \mathrm{~mA}, \operatorname{Si}(111), \theta=14.3^{\circ}$

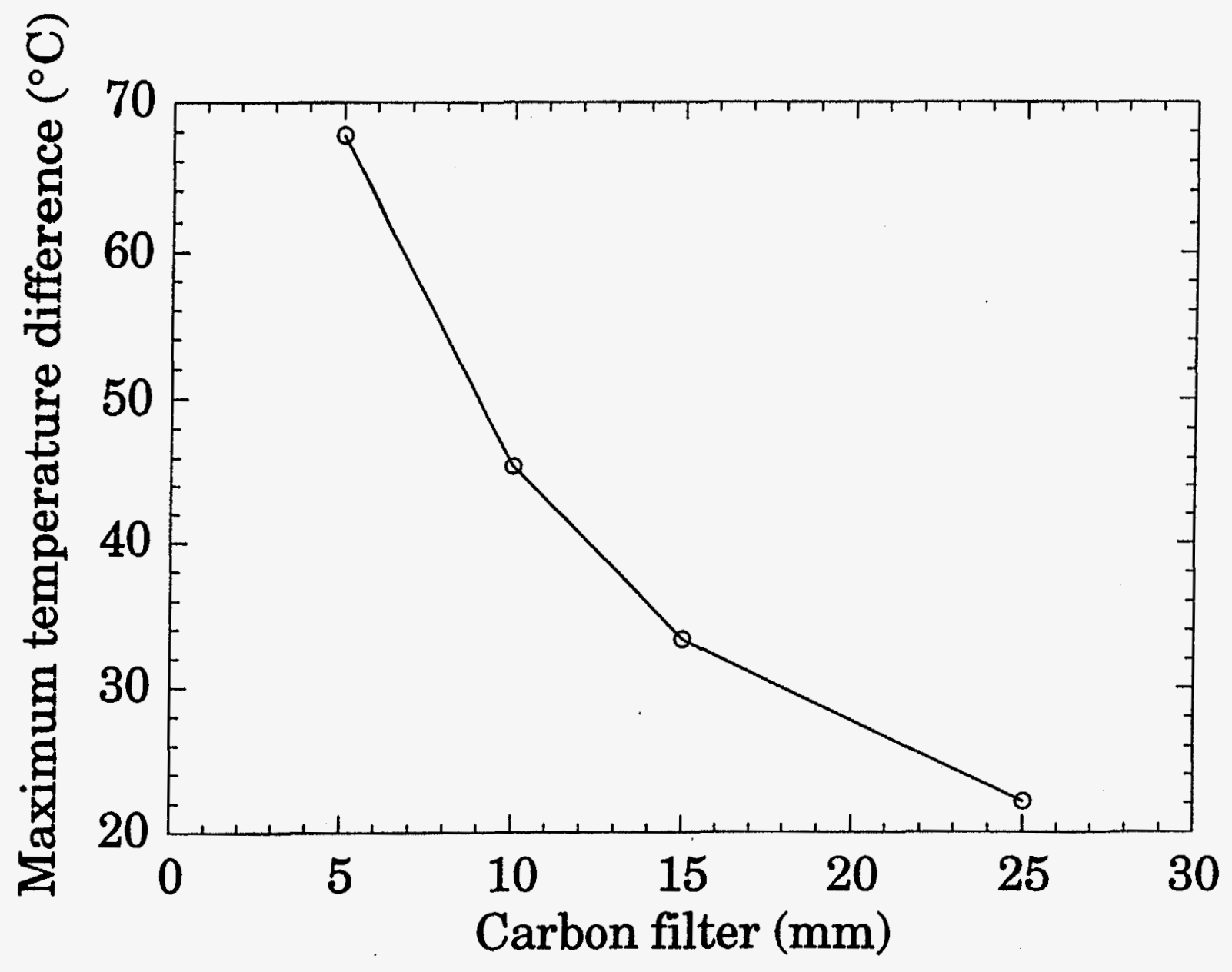



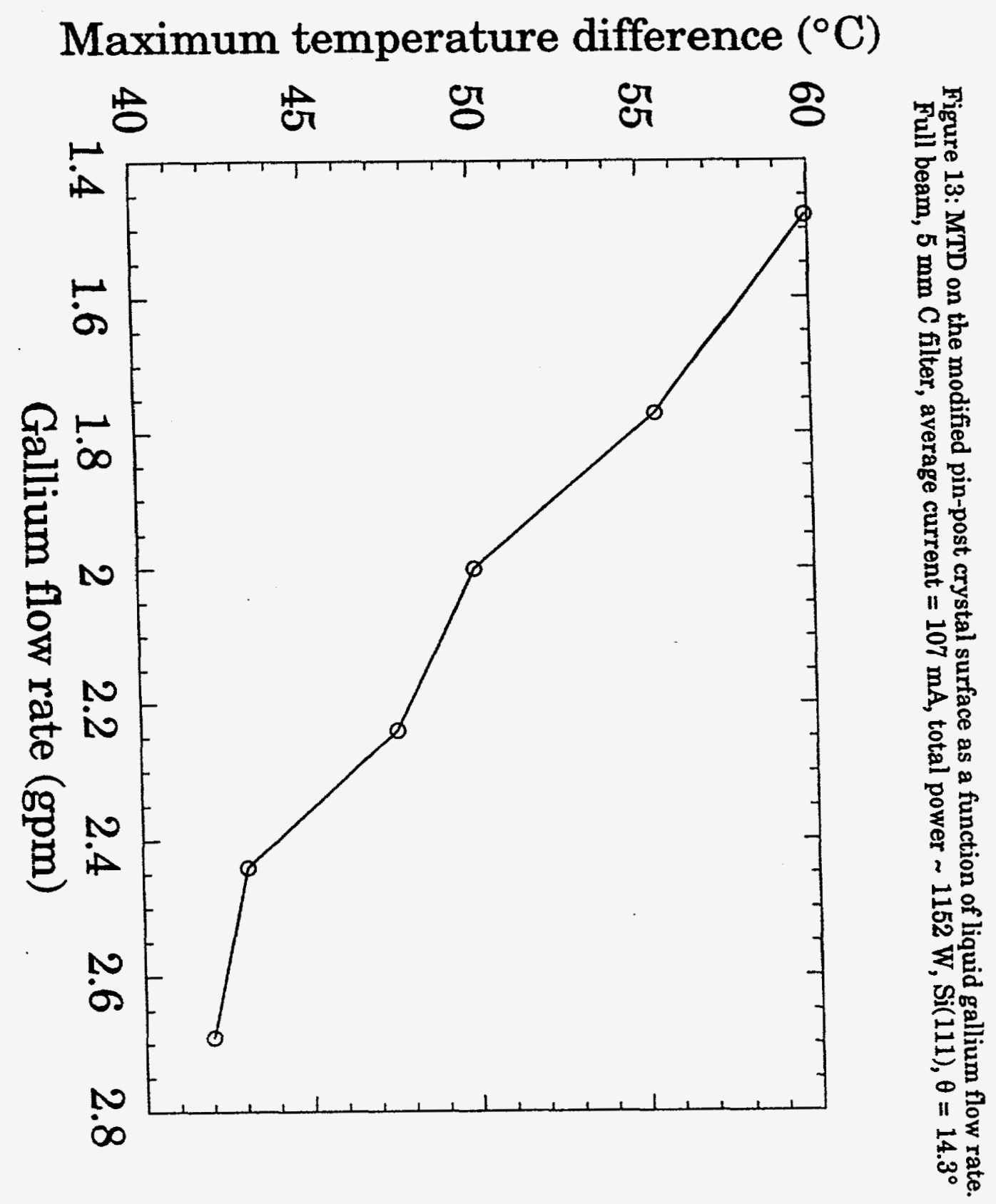


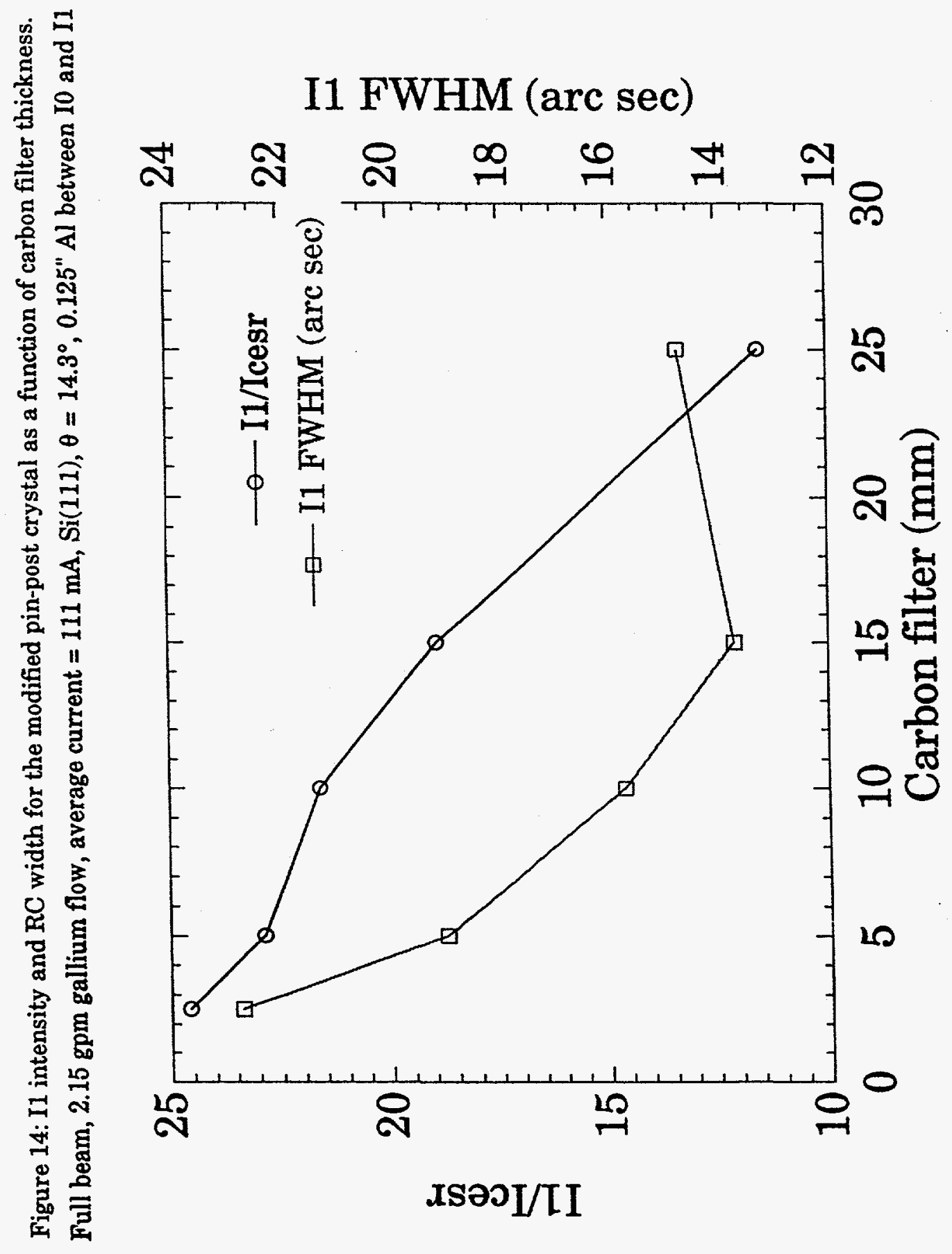


Figure 15: Liquid gallium flow characteristics of the modified pin-post crystal

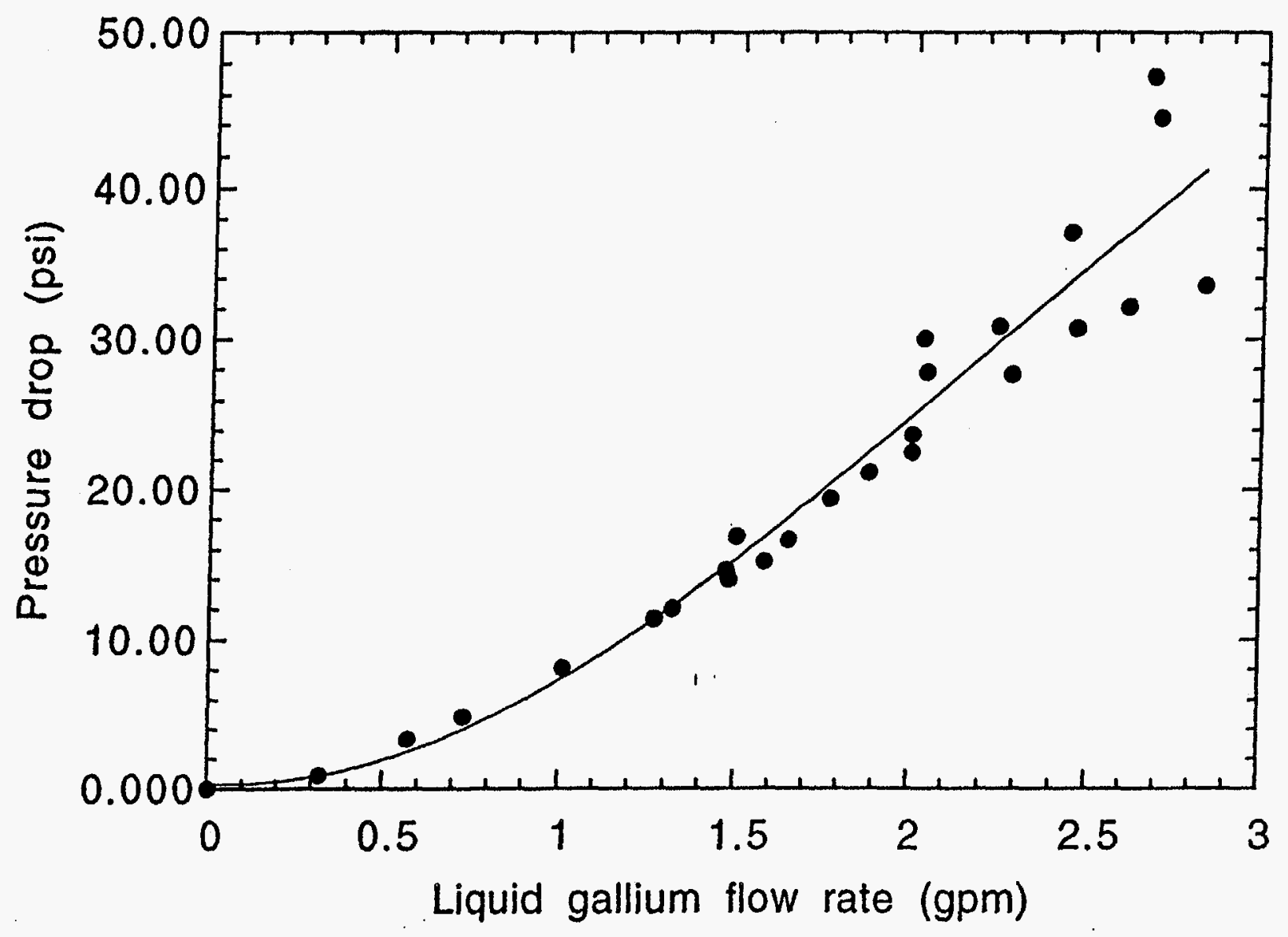




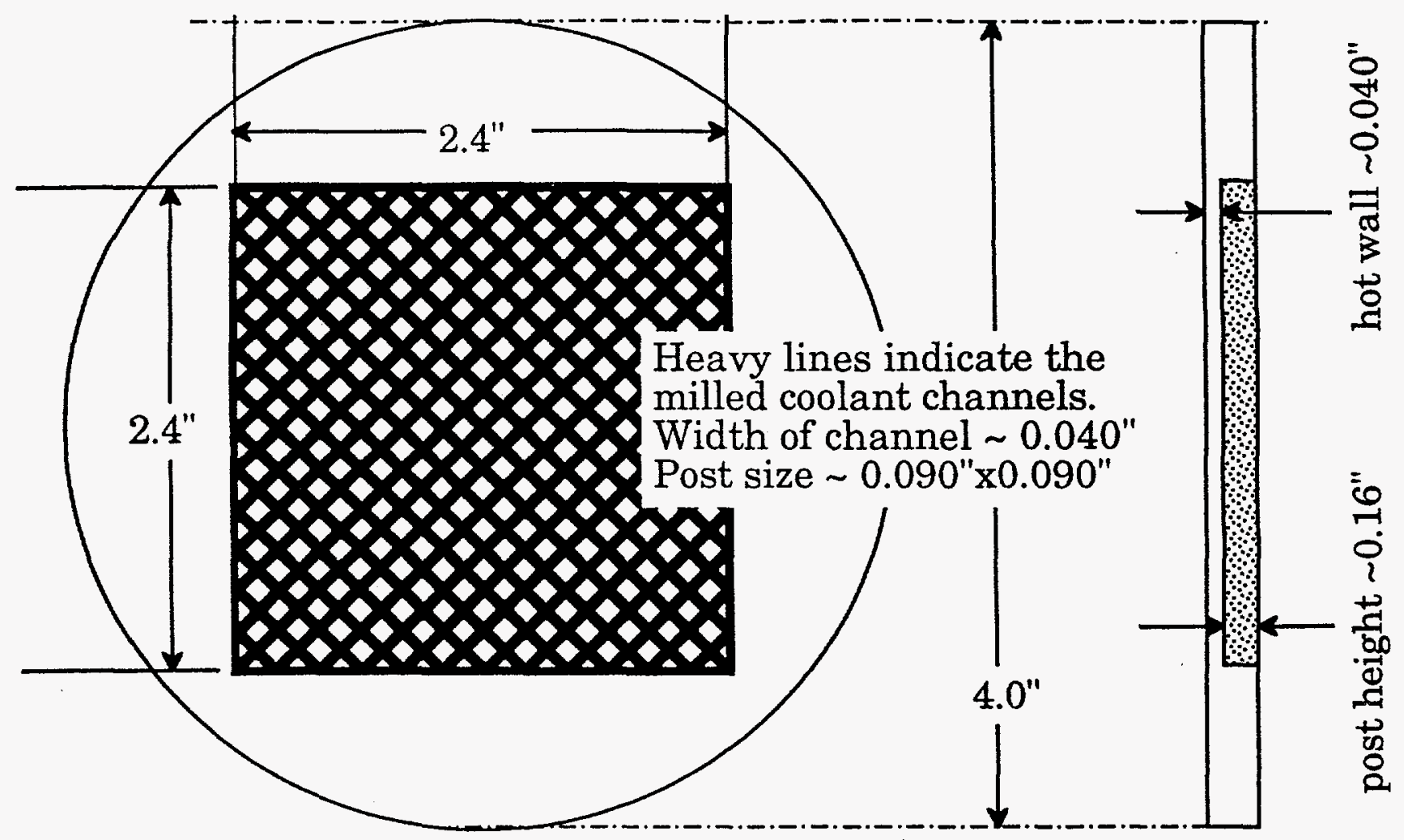

Figure 16a: Sketch of criss-cross crystal

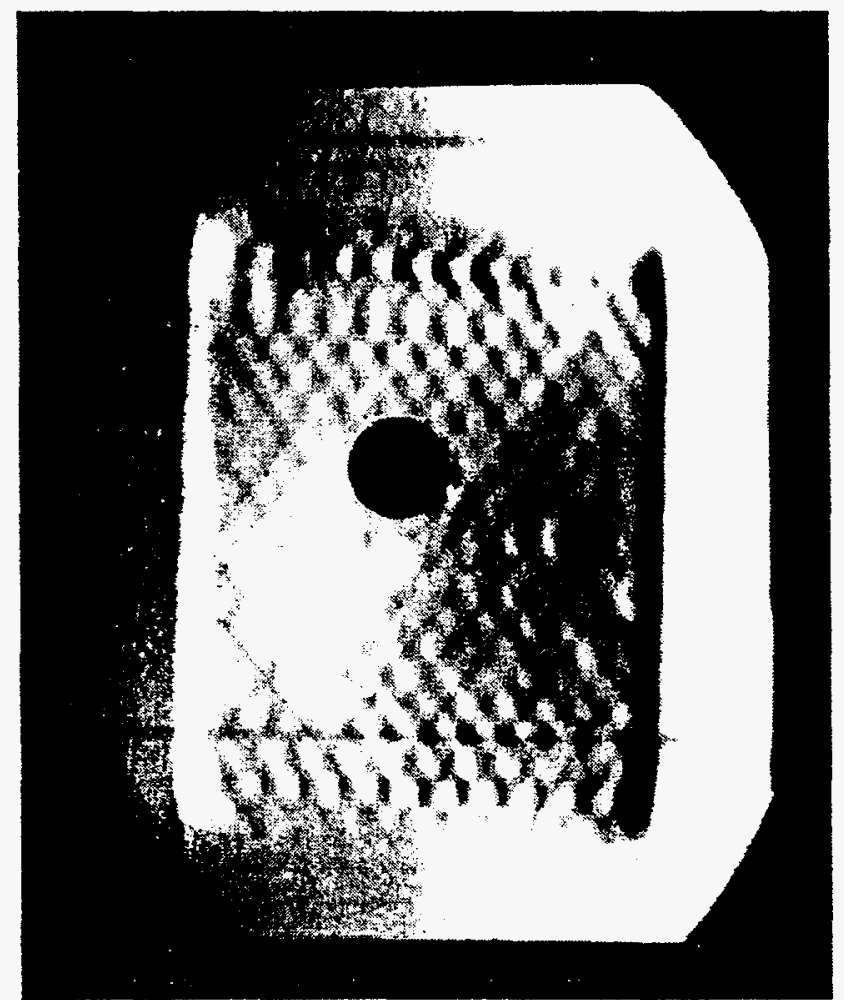

Figure 16b: 8-keV topograph of the criss-cross crystal. The diameter of the dark circle in the center (artifact of the film cassette) is $3 / 8$ inch. 


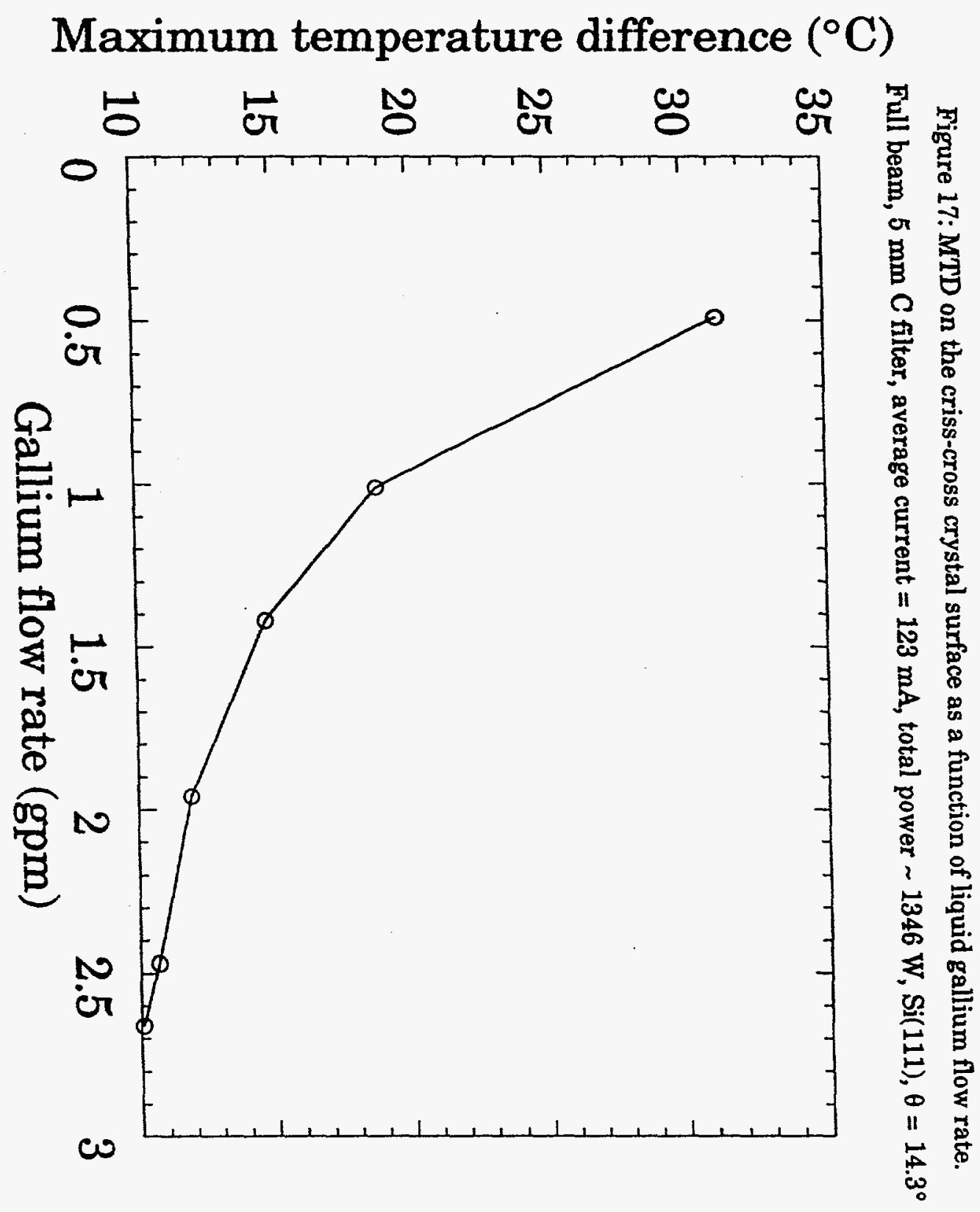




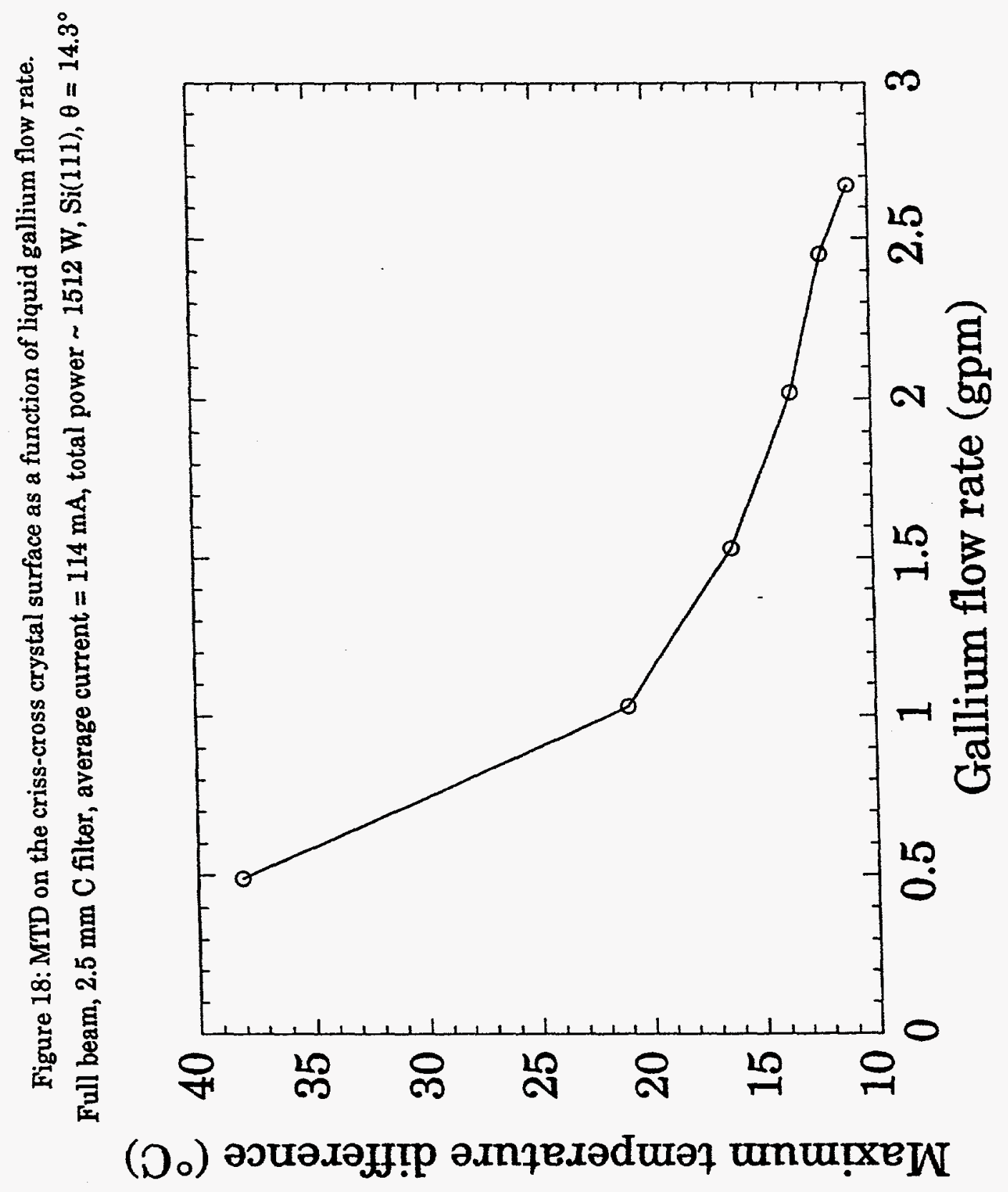


Figure 19: MTD on the criss-cross crystal surface as a function of liquid gallium flow rate.

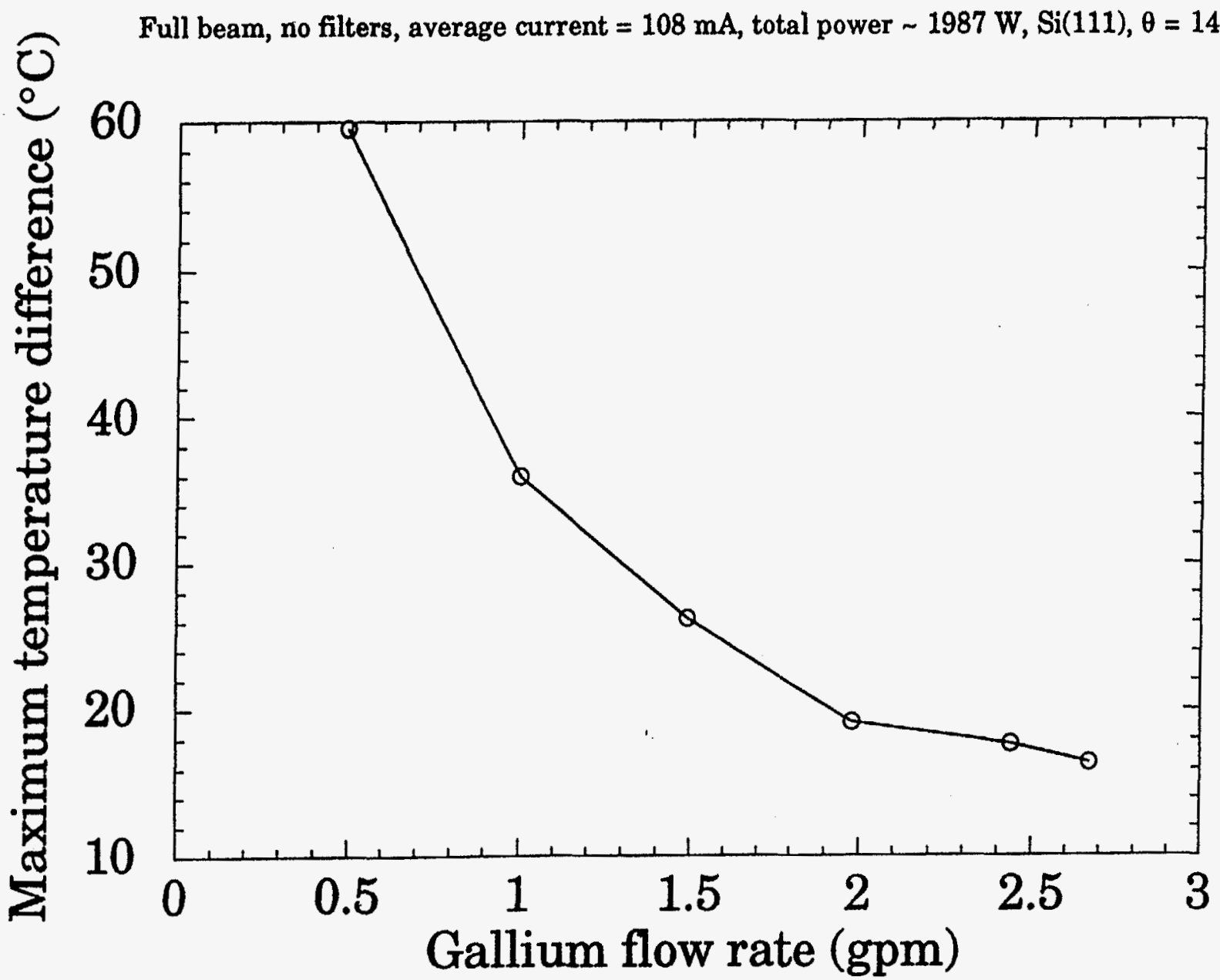


Figure 20: 11 intensity and RC width for the criss-cross crystal as a function of carbon filter thickness.

Full beam, $1.0 \mathrm{gpm}$ gallium flow, average current $=116 \mathrm{~mA}, \operatorname{Si}(111), \theta=14.3^{\circ}$

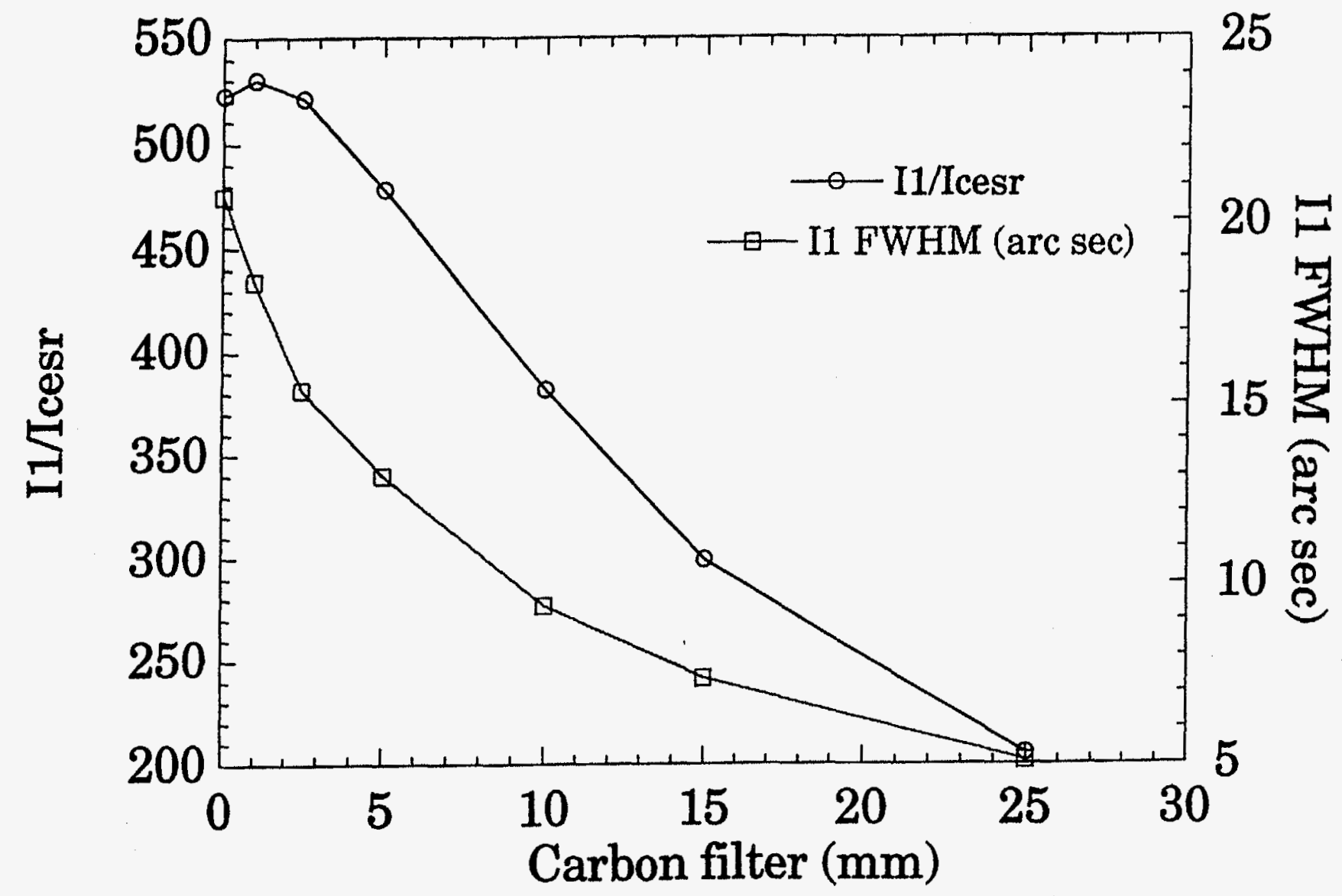


Figure 21: 11 intensity and RC width for the criss-cross crystal as a function of liquid gallium flow rate.

Full beam, no filters, average current $=136 \mathrm{~mA}$, average power $=2502 \mathrm{~W}, \mathrm{Si}(111), \theta=14.3^{\circ}$

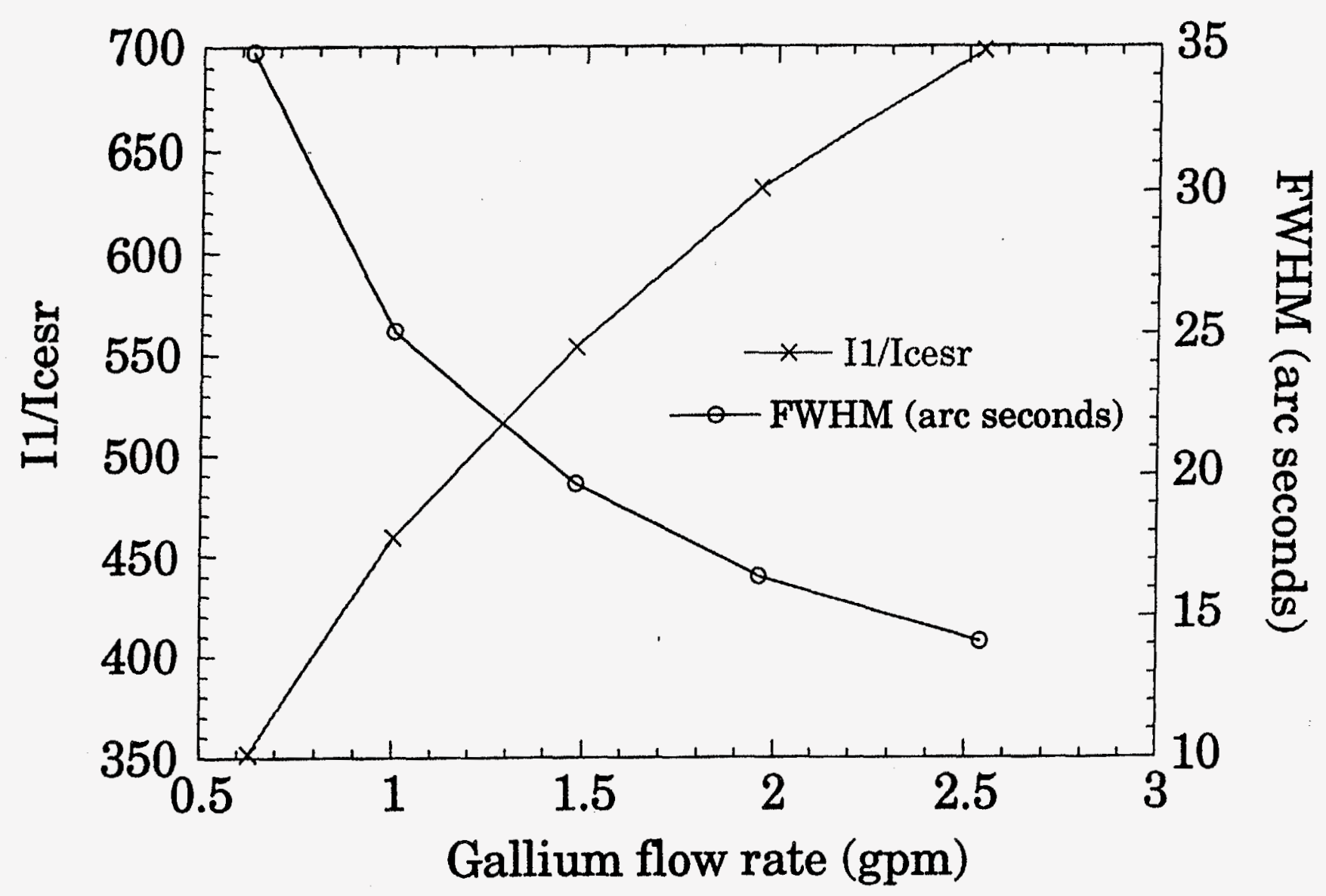


Figure 22: I1 intensity and RC width for the criss-cross crystal as a function of liquid gallium flow rate. Full beam, $25 \mathrm{~mm}$ carbon filter, average current $=117 \mathrm{~mA}$, average power $=2153 \mathrm{~W}, \mathrm{Si}(111), \theta=14.3^{\circ}$

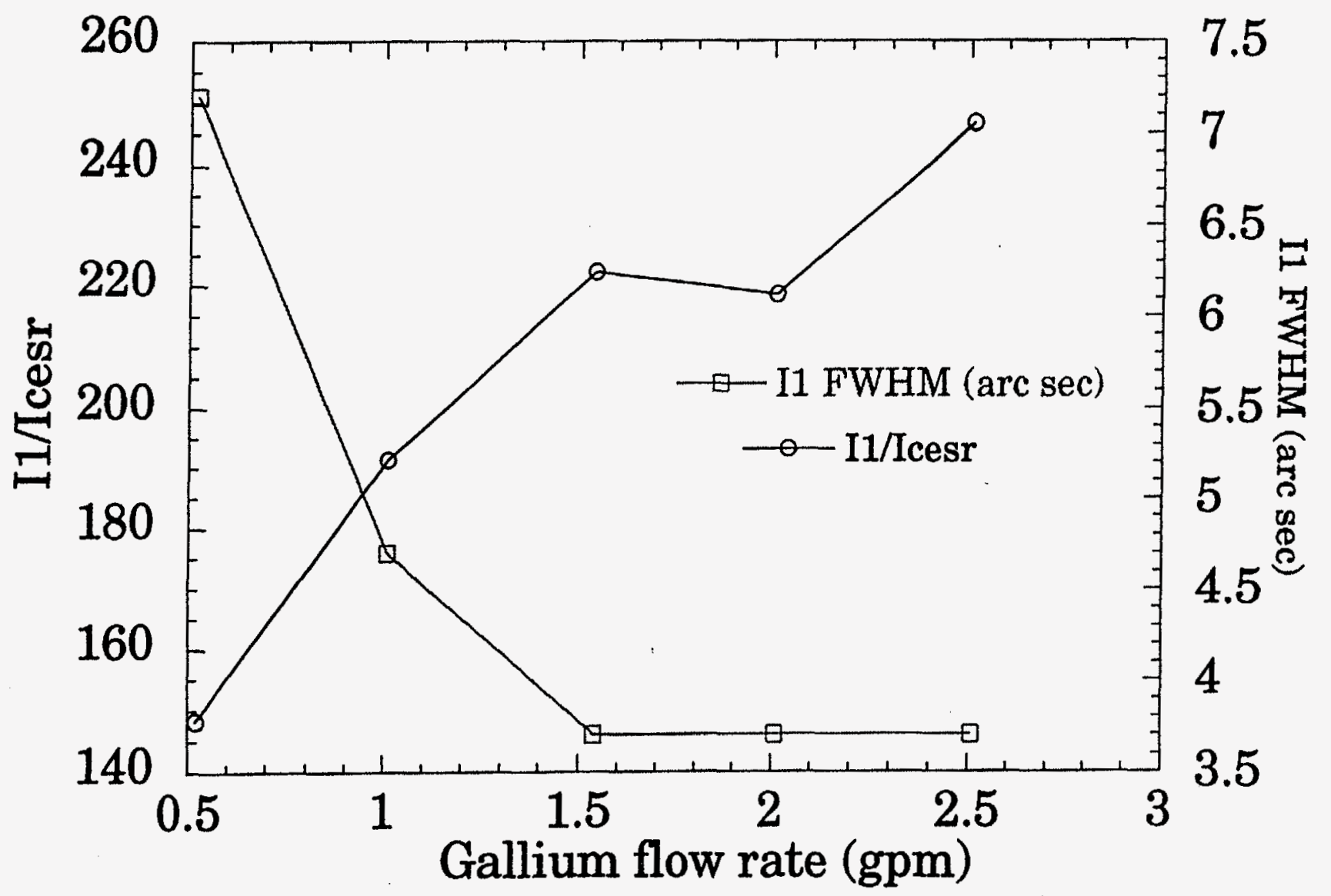




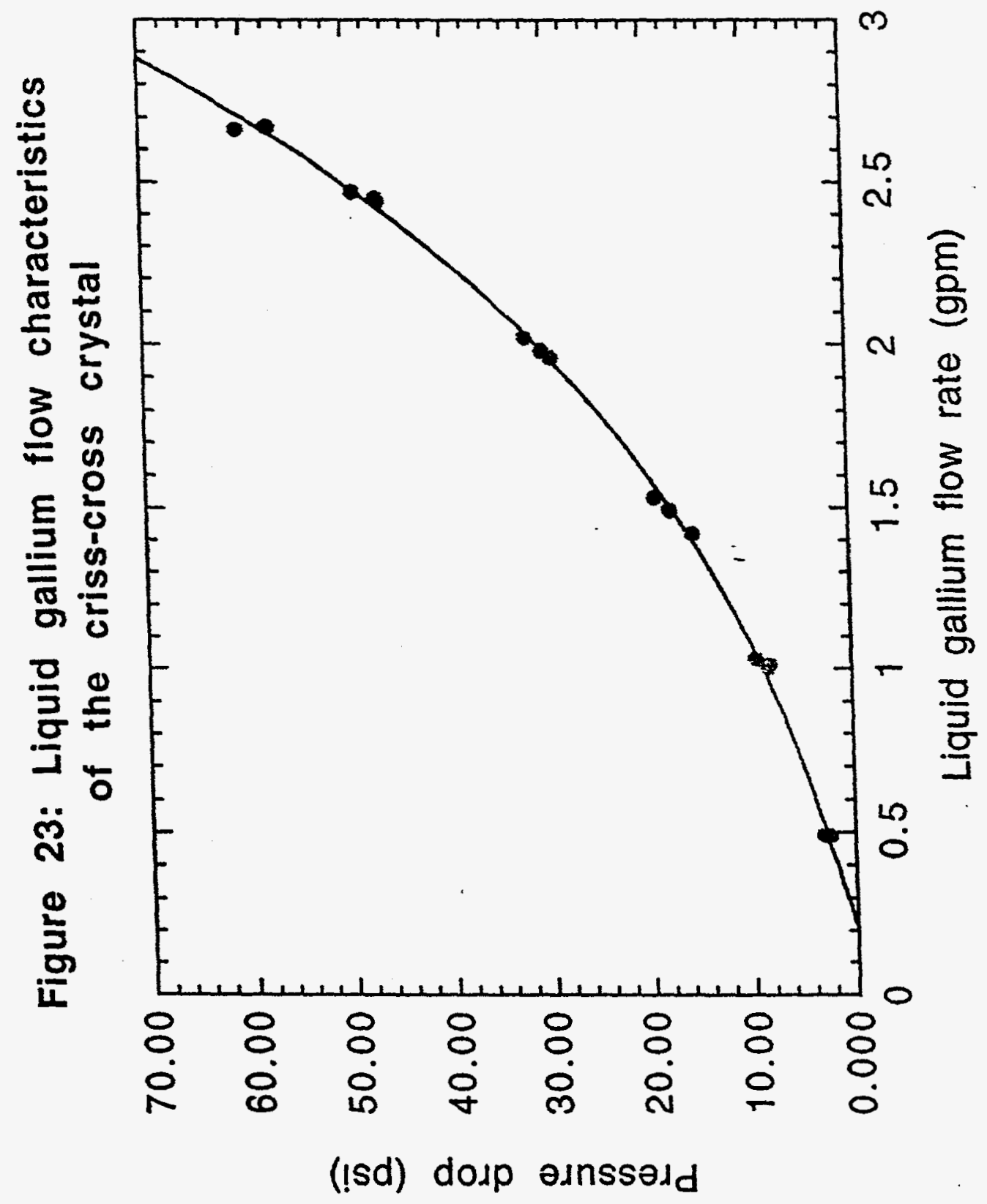




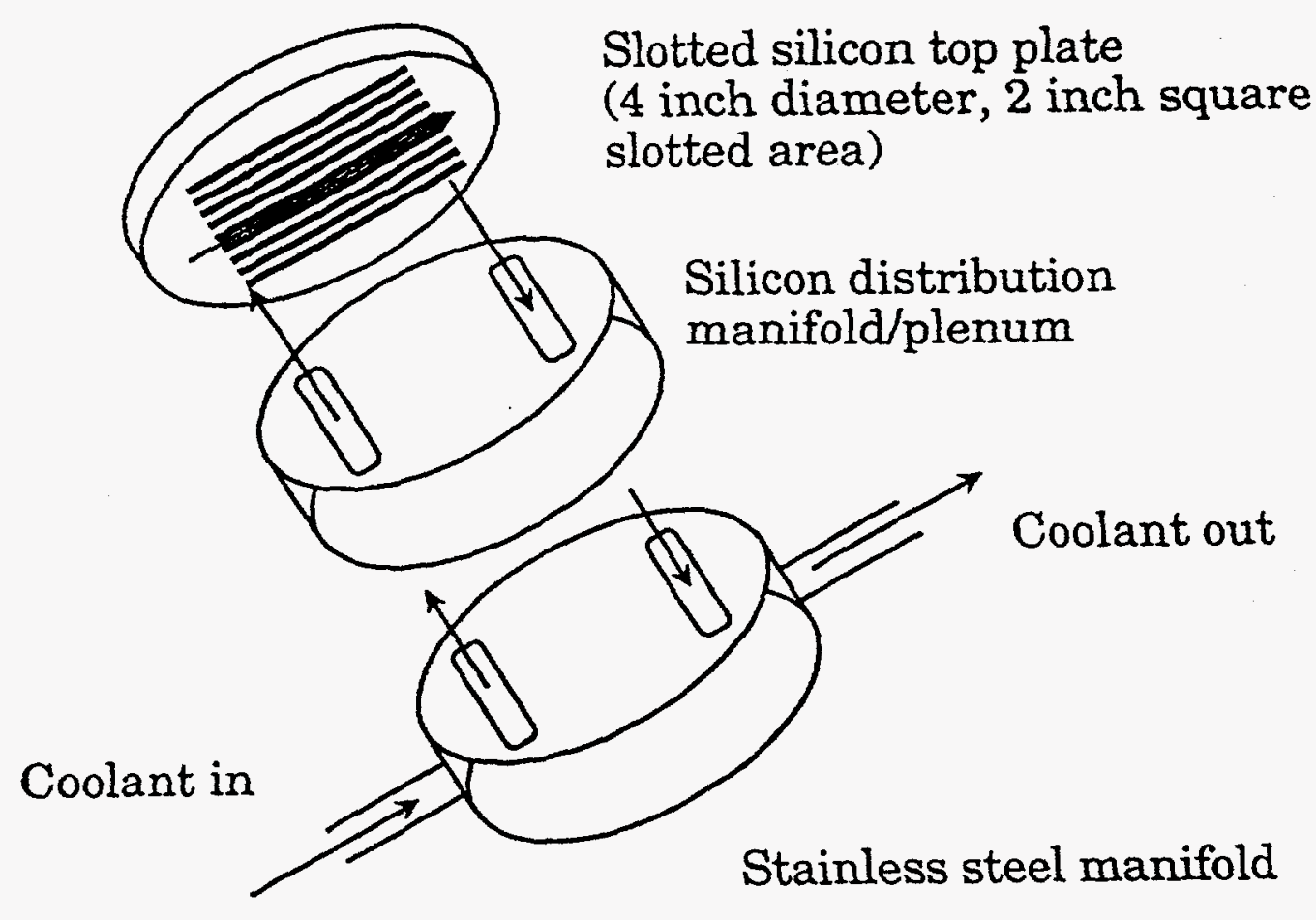

Cross-section of slots

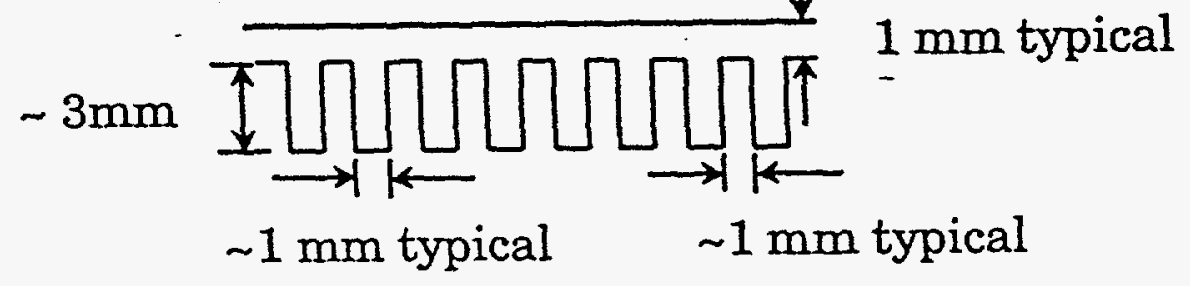

Figure 24a: Sketch of the slotted crystal used in the data presented. The criss-cross crystal has a similar manifold arrangement.

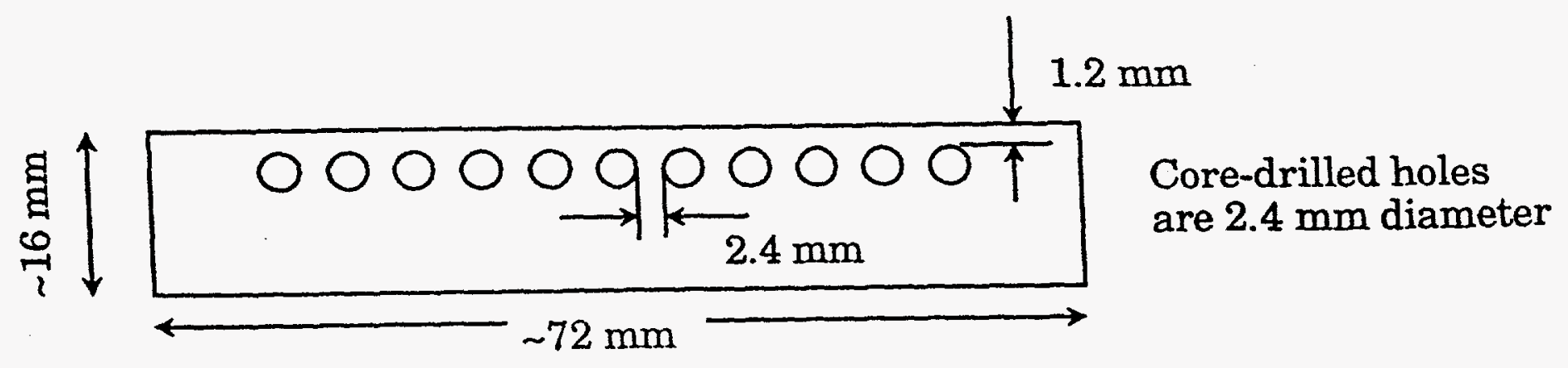

Figure 24b: Sketch of core-drilled crystal used for data presented. 


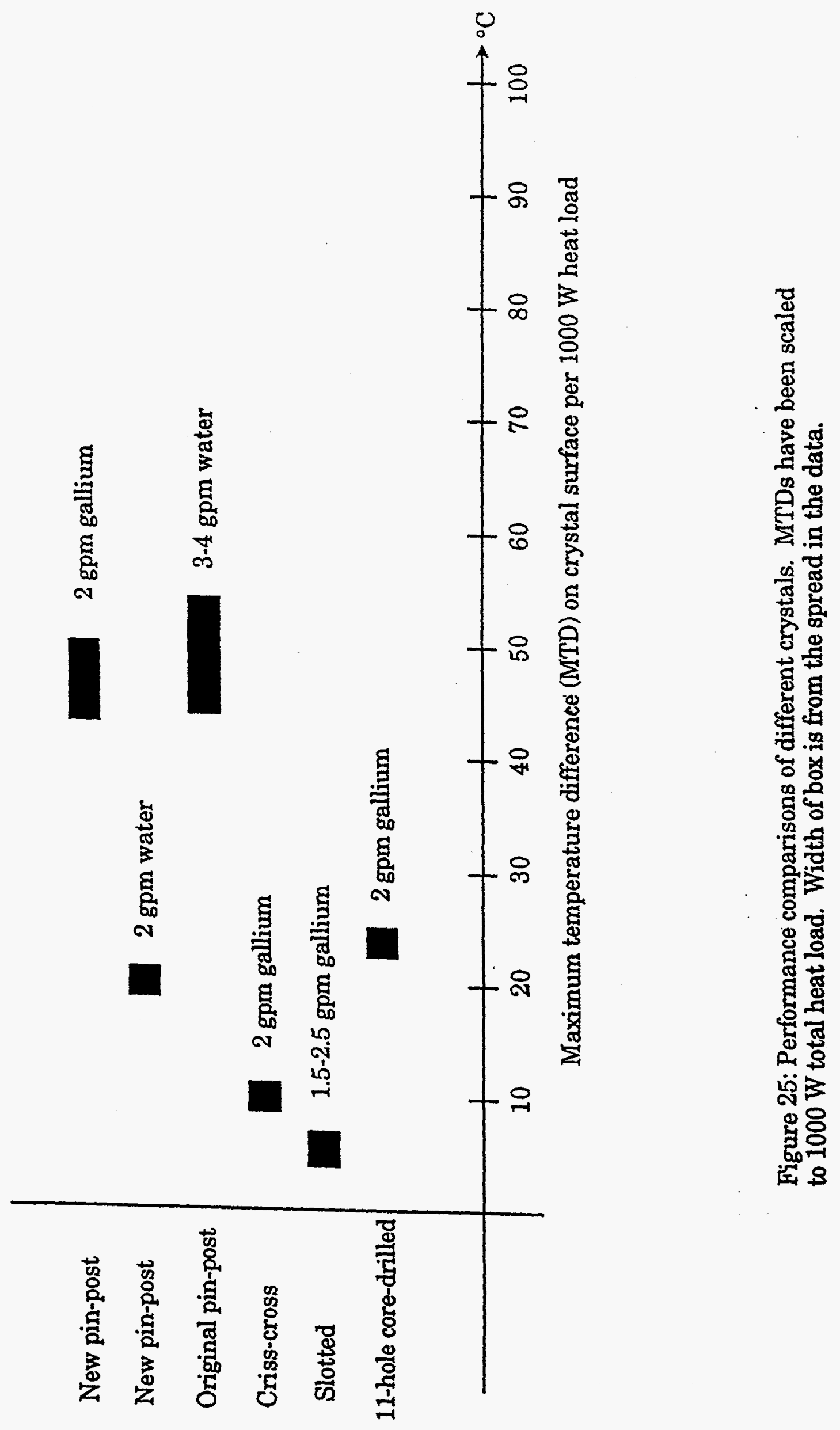




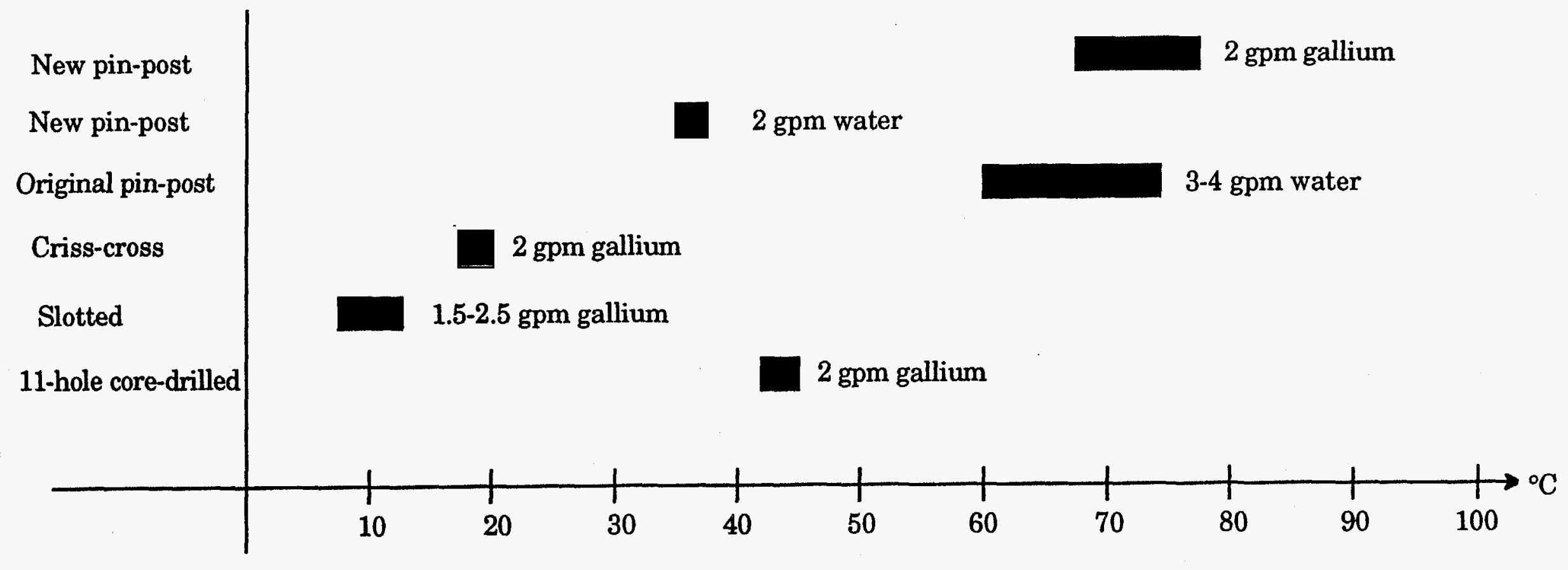

Maximum temperature difference (MTD) on crystal surface per $3.6 \mathrm{~W} / \mathrm{mm}^{2}$ surface power density heat load.

Figure 26: Performance comparison of different crystals. MTDs have been scaled to $3.6 \mathrm{~W} / \mathrm{mm}^{2}$ surface power density. Width of box is from spread in the data. 


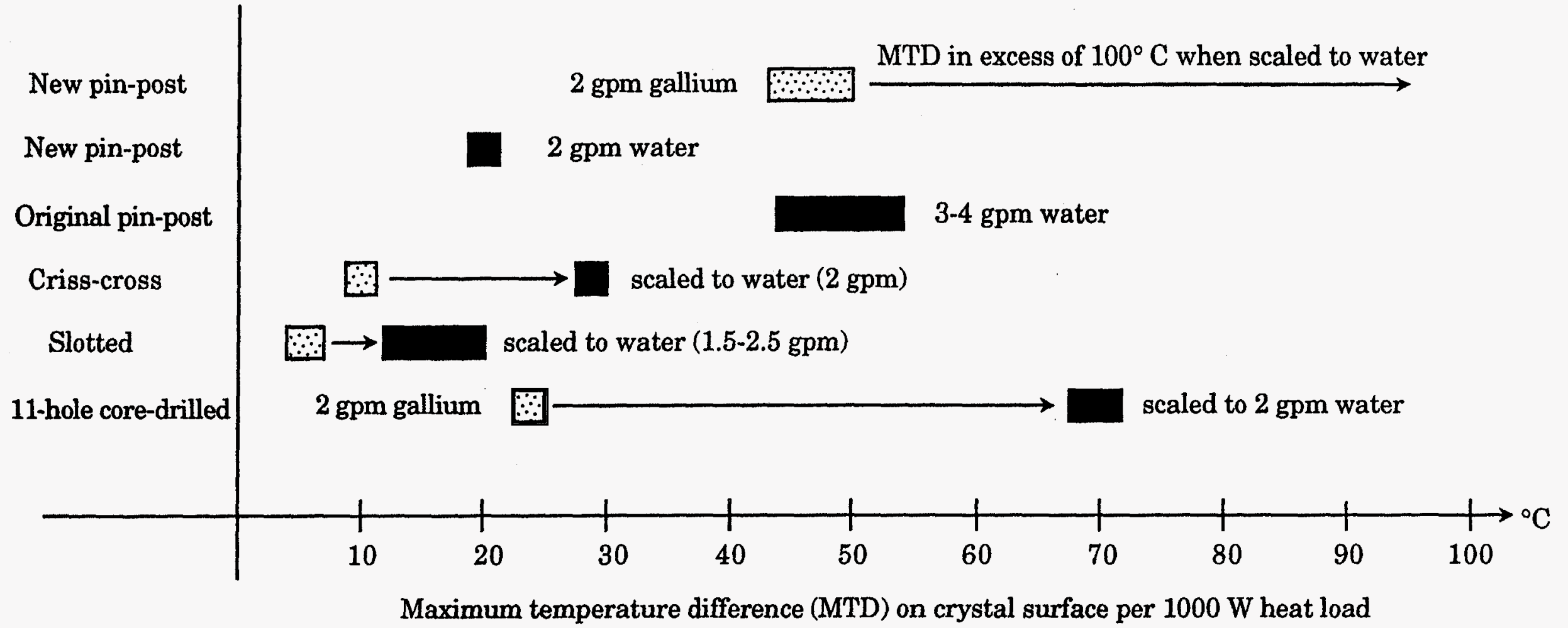

Figure 27: MTD comparisons scaled to $1000 \mathrm{~W}$ total heat load and to water as a coolant. The dotted boxes indicate the MTD for liquid gallium (see figure 25). The assumption is that $\mathrm{MTD}$ (water) = $3 \mathrm{MTD}$ (gallium). 


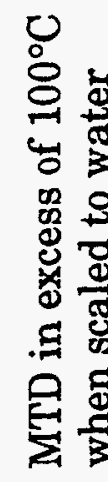

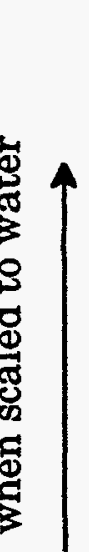

:

䄈

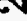

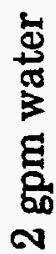

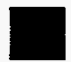

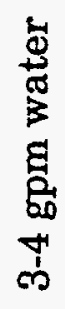

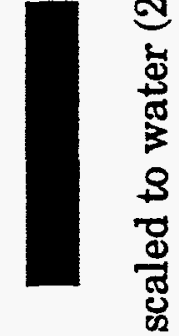

离

द्.

ำ

¿'

可

$\stackrel{\pi}{\pi}$

3

용

总

.

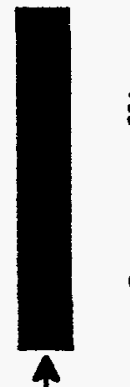

0

0

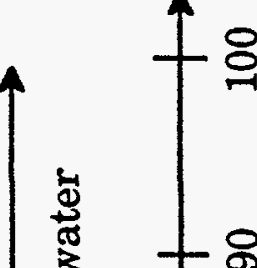

क्ष

蓆

g

$\$$

3 평

오움

영

全查

ซ

过

ठั

ज

‥

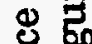

(5)

㗨

뵤

g

吅

ल.

오

马

중

要

足

동

용

용

면

是星

$\therefore$. : 8 శ్

๑ 语要是 


\section{Maximum temperature difference $\left({ }^{\circ} \mathrm{C}\right)$}

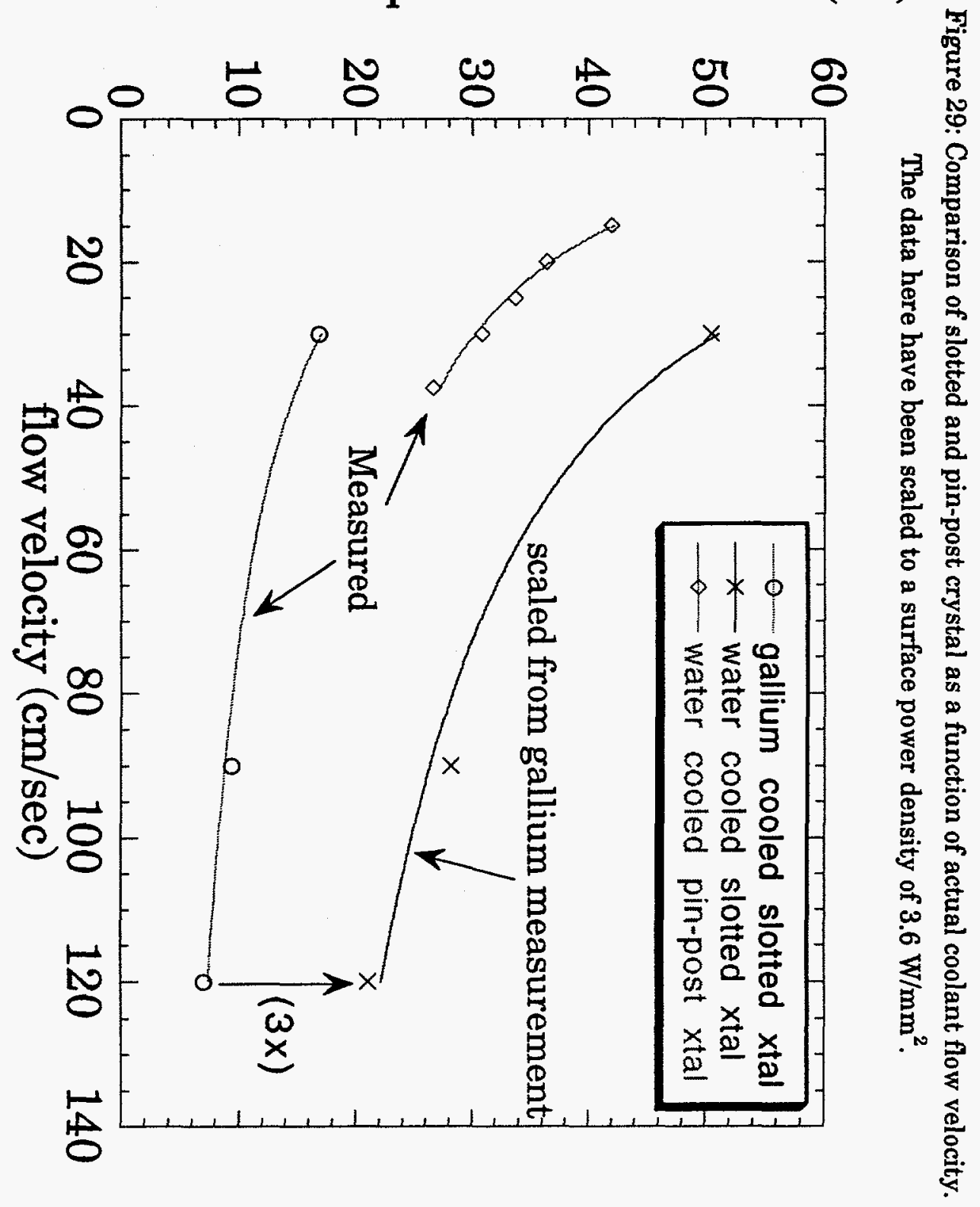

